\title{
THE NECESSITY OF OTHERS IS THE MOTHER OF INVENTION: INTRINSIC AND PROSOCIAL MOTIVATIONS, PERSPECTIVE TAKING, AND CREATIVITY
}

\author{
ADAM M. GRANT \\ University of Pennsylvania \\ JAMES W. BERRY \\ University of North Carolina at Chapel Hill
}

\begin{abstract}
Although many scholars believe that intrinsic motivation fuels creativity, research has returned equivocal results. Drawing on motivated information processing theory, we propose that the relationship between intrinsic motivation and creativity is enhanced by other-focused psychological processes. Perspective taking, as generated by prosocial motivation, encourages employees to develop ideas that are useful as well as novel. In three studies, using both field and lab data, we found that prosocial motivation strengthened the association between intrinsic motivation and independent creativity ratings. In our second and third studies, perspective taking mediated this moderating effect. We discuss theoretical implications for creativity and motivation.
\end{abstract}

As work becomes increasingly dynamic, uncertain, and knowledge-based, organizations depend on creative ideas from employees (George, 2007). Scholars and practitioners share a strong interest in understanding the psychological forces that motivate creativity-the production of ideas that are both novel and useful (Amabile, 1996). For several decades, researchers have believed that intrinsic motivation is an important driver of creativity (Elsbach \& Hargadon, 2006). When intrinsically motivated, employees expend effort based on interest, curiosity, and a desire to learn (Ryan \& Deci, 2000). Intrinsic motivation is thought to enhance creativity by increasing positive affect, cognitive flexibility, risk taking, and persistence (Shalley, Zhou, \& Oldham, 2004).

However, the empirical evidence linking intrinsic motivation to creativity is equivocal (George, 2007; Shalley et al., 2004). Some studies have demonstrated that intrinsic motivation is associated with higher levels of creativity (e.g., Amabile, 1985; Amabile, Hill, Hennessey, \& Tighe, 1994), whereas others have shown weak or nonsignificant associa-

For novel and useful feedback, we thank Elizabeth Morrison, David Mayer, Ron Piccolo, and Manuela Priesemuth. For enlightening discussions, we thank Teresa Amabile, Sigal Barsade, and Jen Mueller. For assistance with data collection and editing, we thank Francesca Gino, Ted Henifin, Chris Myers, Maggie O’Brien, and Marty Whelan.

This article was accepted before the first author became an associate editor of this journal. tions (e.g., Dewett, 2007; Perry-Smith, 2006; Shalley \& Perry-Smith, 2001). In light of these conflicting findings, George (2007: 445) observed that "rather than assume that intrinsic motivation underlies creativity, researchers need to tackle this theorized linkage more directly and in more depth." Organizational scholars need new theoretical perspectives and empirical investigations to deepen knowledge of the motivational processes that drive creativity (Shalley et al., 2004).

Our objective in this article is to explain and resolve the inconsistent relationship between intrinsic motivation and creativity. To do so, we draw on motivated information processing theory from social psychology, which offers a promising conceptual framework for both explaining and resolving the inconsistency. The core premise of motivated information processing theory is that motivations shape cognitive processing: employees selectively notice, encode, and retain information that is consistent with their desires (Kunda, 1990; Nickerson, 1998). Thus, when employees are intrinsically motivated, their desires to learn, explore their interests, and engage their curiosity will lead them to focus on novel ideas. However, to produce creative ideas, employees also need to attend to usefulness. We propose that since ideas are ultimately most useful when they solve problems for other people inside and outside an organization, a focus on usefulness can be engendered by perspective taking. When employees take others' perspectives, they are more likely to develop ideas that are useful to others (Mohrman, Gibson, \& Mohrman,

Copyright of the Academy of Management, all rights reserved. Contents may not be copied, emailed, posted to a listserv, or otherwise transmitted without the copyright holder's express written permission. Users may print, download or email articles for individual use only. 
2001). Recent developments in motivated information processing theory suggest that employees are likely to attend to usefulness when they experience prosocial motivation-the desire to benefit others-which encourages them to consider others' perspectives (De Dreu, Weingart, \& Kwon, 2000). We thus hypothesize that when guided by prosocial motivation to take others' perspectives, employees will channel their intrinsic motivation toward producing ideas that are not only novel, but also useful, thereby achieving higher creativity. We tested these hypotheses in two field studies and a laboratory experiment.

Our theoretical perspective and empirical findings offer important contributions to knowledge about creativity and motivation in work organizations. Our research answers calls to identify moderators of the relationship between intrinsic motivation and creativity (George, 2007; Shalley et al., 2004) by accentuating the importance of other-focused psychological processes in creativity. Our motivated information processing viewpoint reveals how perspective taking, fueled by prosocial motivation, leads employees to channel their intrinsic motivation toward ideas that are useful as well as novel. Our research also has two central theoretical implications beyond those of existing research on the interaction of intrinsic and prosocial motivations (Grant, 2008). First, we identify perspective taking as a key mechanism through which prosocial motivation strengthens the impact of intrinsic motivation on creativity, addressing Grant's (2008) call to build and test theory about the psychological processes that explain this interaction. Second, in doing so, we introduce perspective taking as an important influence on creativity, showing how a focus on others can encourage employees to direct their intrinsic motivation toward the generation of creative ideas. Our research shows how perspective taking interacts with intrinsic motivation to enhance creativity.

\section{MOTIVATION AND CREATIVITY}

Our emphasis in this article is on understanding the conditions under which intrinsic motivation promotes creativity. Intrinsic motivation refers to the desire to expend effort based on interest in and enjoyment of the work that is being performed (Amabile, 1996; Ryan \& Deci, 2000). As noted above, psychologists and organizational scholars have long believed that intrinsic motivation is an important enabler of creativity. Researchers have identified three interrelated psychological mechanisms through which intrinsic motivation may stimulate creativity. First, emotion theorists have proposed that when employees are intrinsically motivated, they experience positive affect (e.g., Silvia, 2008). This stimulates creativity by broadening the range of cognitive information available, expanding the scope of attention toward assimilating a wider set of ideas, and encouraging cognitive flexibility for identifying patterns and associations between ideas (e.g., Amabile, Barsade, Mueller, \& Staw, 2005; Fredrickson, 1998). Second, self-determination theorists have proposed that when employees are intrinsically motivated, their curiosity and interest in learning will enhance their cognitive flexibility, willingness to take risks, and openness to complexity, which in turn will expand their access to ideas and potential solutions (Gagné \& Deci, 2005; see also Amabile, 1979, 1996).

Third, both emotion and self-determination theorists suggest that intrinsic motivation promotes creativity by encouraging persistence. From the standpoint of emotion theories, by fostering positive affect, intrinsic motivation enhances psychological engagement and builds energy for sustaining effort, increasing the amount of time that employees are willing and able to work on their tasks (e.g., Fredrickson, 1998). From the standpoint of self-determination theory, by fostering confidence and interest, intrinsic motivation encourages employees to persist with challenging, complex, unfamiliar tasks (Gagné \& Deci, 2005), as well as to concentrate their attention more effectively on these tasks (e.g., Amabile, 1996).

\section{Conflicting Results}

However, empirical research has yielded mixed and often confusing results about whether intrinsic motivation enhances creativity (for reviews, see Amabile and Mueller [2007], George [2007], and Shalley et al. [2004]). Most of this research has involved laboratory experiments with children and college students developing artistic products, in which it is possible to manipulate intrinsic motivation and obtain independent expert ratings of creative outcomes. A number of laboratory experiments have shown that when participants are induced to experience high levels of intrinsic motivation, their products are rated as more creative (e.g., Amabile, 1979; Koestner, Ryan, Bernieri, \& Holt, 1984). However, other laboratory experiments have shown weak, mixed, or no benefits of intrinsic motivation for creativity (e.g., Amabile, 1985; Amabile, Hennessey, \& Grossman, 1986; Eisenberger \& Aselage, 2009; Shalley \& Perry-Smith, 2001). For example, Amabile et al. (1986: 21) stated that several laboratory studies "do not allow definitive conclusions ... only some of the various intrinsic in- 
terest measures showed correlations with creativity." They further noted these studies are vulnerable to the possibility of reverse causality. Rather than causing creativity, self-reports of intrinsic motivation "might result from a greater enjoyment and satisfaction experienced" in expressing creativity (Amabile et al., 1986: 21). Table 1 summarizes key details of the pertinent laboratory studies, showing that intrinsic motivation has been more consistently linked to creativity in artwork and writing tasks than to creativity in producing ideas and solutions relevant to business problems.

The results of field studies have also been equivocal. Studies with college students have shown that intrinsic motivation is correlated with higher observer ratings of creativity (Amabile et al., 1994), but studies with working adults have returned conflicting results, with intrinsically motivated employees being rated as more creative in some samples and tasks, but not in others (Amabile et al., 1994; Dewett, 2007; Eisenberger \& Aselage, 2009; Eisenberger \& Rhoades, 2001; Janssen \& van Yperen, 2004; Perry-Smith, 2006; Shin \& Zhou, 2003; Tierney, Farmer, \& Graen, 1999). Table 1 provides further information on these field studies, suggesting that intrinsic motivation more consistently predicts self-reports of creativity than observer ratings or archival measures of creativity.

Taken together, these laboratory and field studies suggest a variable relationship between intrinsic motivation and creativity, and this variability has received surprisingly little theoretical and empirical attention. In recent reviews of the creativity literature, organizational scholars have called for new conceptual frameworks and studies to investigate the conditions under which intrinsic motivation is more and less likely to fuel creativity (Amabile \& Mueller, 2007; George, 2007; Shalley et al., 2004). Our focus is on answering these calls to examine contingencies that moderate the impact of intrinsic motivation on creativity.

Existing research provides clues about why intrinsic motivation does not guarantee that employees will ultimately produce ideas that are novel and useful (Amabile, 1996). Several studies have shown that novelty and usefulness are independent, and typically orthogonal, dimensions of creativity. As Litchfield (2008: 659) summarized, "Creativity is generally treated as a composite of novelty and utility . . . but research has yet to carefully examine the effects of these dual goals . . novelty and usefulness are unrelated dimensions of ideas." Furthermore, Ford and Gioia (2000: 727) demonstrated that "different factors independently influence" novelty and usefulness. The studies summarized in Table 1 appeared to more consistently link intrinsic motivation with creativity in tasks that focused primarily on novelty and originality—such as creating artwork and writing poems-than in tasks with stronger usefulness components, as are common in research and development jobs. This evidence provides reason to believe that intrinsic motivation drives the production of novel, but not necessarily useful, ideas.

Why might intrinsic motivation promote a stronger focus on novelty than on usefulness? The conceptual framework of motivated information processing theory provides a parsimonious explanation. As noted previously, motivated information processing is a pervasive human tendency to selectively perceive, encode, and retain information that is congruent with one's desires (for reviews, see Heath, Larrick, and Klayman [1998]; Kunda [1990]; and Nickerson [1998]). When employees are intrinsically motivated, they experience a desire to learn, pursue their interests, and explore their curiosities (Ryan \& Deci, 2000). Thus, intrinsic motivation is likely to encourage employees to focus primarily on ideas that are novel, original, and unique, which provide the greatest opportunities for learning and exploration. Indeed, research has shown that intrinsically motivated employees use interest as a guide for determining which ideas to pursue (Amabile et al., 1994; Ryan \& Deci, 2000) and that interest primarily directs attention to ideas that are novel (Silvia, 2008). When intrinsically motivated, employees engage in exploration (Ryan \& Deci, 2000), becoming psychologically absorbed in the process of working on their tasks (Amabile et al., 1994; Gagné \& Deci, 2005) and often viewing the development of novel ideas as an end in and of itself (Csikszentmihalyi, 1996). Summarizing three decades of self-determination research, Ryan and Deci (2000: 71) stated that intrinsic motivation focuses attention on "activities that have the appeal of novelty."

Intrinsic motivation thus promotes a focus on seeking out new discoveries, which is associated with developing products that are higher in originality but not in aspects related to usefulness, such as technical quality (Csikszentmihalyi \& Getzels, 1971). Further, classic psychological research has shown that many intrinsically motivated architects had difficulty producing creative ideas because they were focused on the novelty of their designs but not necessarily concerned with their usefulness (Barron, 1963; for a recent discussion, see Little [2006]). Reviewing a growing body of research on interest, Silvia (2008: 58) further explained that "interest attracts people to new, unfamiliar things, and many of these things will turn out to be trivial." 
TABLE 1

Summary of Studies Linking Intrinsic Motivation and Creativity

Study and Context

Laboratory study with female college students making collages (Amabile, 1979)

Laboratory study with 1st and 2nd grade children painting (Koestner et al., 1984)

Laboratory study with young adults who self-identified as creative writers asked to write two poems (Amabile, 1985)

Laboratory study with elementary school children making collages, writing stories, and solving puzzles (Study 1, Amabile et al., 1986)

Laboratory study with college students making collages (Study 3, Amabile et al., 1986)

Laboratory study with college students generating solutions to two business problems (Shalley \& PerrySmith, 2001)

Laboratory study with college students suggesting creative titles for a short story (Study 3, Eisenberger \& Aselage, 2009)

Field study of employees in diverse jobs (Study 2, Eisenberger \& Aselage, 2009)

Field study of employees in a sales organization (Study 4, Eisenberger \& Rhoades, 2001)

Field study of multiple samples of students and working adults (Amabile et al., 1994)

Field study of R\&D personnel (Dewett, 2007)

Field study in Dutch energy supplier (Janssen \& van Yperen, 2004)
Relevant Manipulations and Measures

Manipulated expected evaluation (yes/no); measured intrinsic motivation (self-report) and creativity (artist ratings).

Manipulated external limits; measured intrinsic motivation (self-report, task persistence) and creativity (judge ratings).

First poem served as baseline; manipulated attention to reasons for writing (intrinsic, extrinsic, none); measured creativity (poet ratings).

Manipulated task rewards; measured intrinsic motivation (self-report and behavioral choice to spend free time on the task a week later) and creativity (teacher ratings).

Manipulated task rewards; measured intrinsic motivation (self-reports of enjoyment, satisfaction, interest, and motivation) and creativity (artist ratings).

Manipulated expectations of external evaluation (controlling, informational); measured intrinsic motivation (self-report) and creativity (expert judges).

Manipulated rewards for creativity; measured intrinsic interest (self-report) and creativity (research assistant ratings).

Employees reported intrinsic interest; supervisors rated creativity.

Employees reported intrinsic task interest; supervisors rated creativity.

Employees reported intrinsic motivational orientation and creativity; independent ratings of creativity on various tasks.

Employees reported intrinsic motivation and creativity; supervisors rated creativity.

Employees reported intrinsic interest (mastery orientation); supervisors rated creative/innovative performance.
Results

Participants who did not expect evaluation reported higher intrinsic motivation and produced artwork judged as more creative.

Controlling limits decreased both measures of intrinsic motivation and both measures of creativity.

Concentrating on extrinsic reasons led to lower creativity ratings on the second poem, but intrinsic reasons did not increase creativity relative to the control (no reasons).

Self-reports of intrinsic motivation were not significantly correlated with creativity for collages, stories, or puzzles; behavioral choice correlated positively with creativity in stories but not collages or puzzles.

Creativity was significantly related to enjoyment and satisfaction, but not interest or motivation.

Informational evaluation increased intrinsic motivation and creativity, but intrinsic motivation was not significantly associated with creativity.

Reward increased intrinsic interest and creativity, but intrinsic interest was not significantly associated with creativity.

Significant, positive correlation between intrinsic interest and creativity.

Significant, positive correlation between intrinsic task interest and creativity.

Intrinsic motivation was significantly associated with creativity in some tasks but not others.

Intrinsic motivation predicted self-reports but not all supervisor ratings of creativity.

Intrinsic interest predicted supervisor ratings of creativity, but not after leadermember exchange was controlled for. 
TABLE 1

(Continued)

\begin{tabular}{lcc}
\hline \multicolumn{1}{c}{ Study and Context } & Relevant Manipulations and Measures & Results \\
\hline $\begin{array}{l}\text { Field study of scientists } \\
\text { (Perry-Smith, 2006) }\end{array}$ & $\begin{array}{c}\text { Employees reported intrinsic motivation; supervisors } \\
\text { rated creativity. }\end{array}$ & $\begin{array}{c}\text { Intrinsic motivation was not significantly } \\
\text { associated with creativity. }\end{array}$ \\
$\begin{array}{l}\text { Field study in R\&D (Shin \& } \\
\text { Zhou, 2003) }\end{array}$ & $\begin{array}{c}\text { Employees reported intrinsic motivation; supervisors } \\
\text { rated creativity. }\end{array}$ & $\begin{array}{c}\text { Intrinsic motivation predicted higher } \\
\text { creativity. }\end{array}$ \\
$\begin{array}{l}\text { Field study of R\&D } \\
\text { employees in a chemical } \\
\text { company (Tierney et al., }\end{array}$ & $\begin{array}{c}\text { Employees reported intrinsic motivational } \\
\text { orientation; creativity was measured with } \\
\text { 1999) }\end{array}$ & $\begin{array}{c}\text { Intrinsic motivational orientation predicted } \\
\text { supervisor ratings, but not the number of } \\
\text { creative research reports. }\end{array}$ \\
\hline
\end{tabular}

This evidence suggests, as predicted by motivated information processing theory, that by drawing attention to interest, intrinsic motivation cultivates a primary focus on novelty but not necessarily on usefulness. Indeed, Amabile (1996: 118) proposed that early stages of the creative process, "where the novelty of the outcome is importantly determined, may require intrinsic motivation," but in advancing toward "stages where the novelty of the work (though still important) is less crucial," other motivators "may serve to focus and energize the individual toward getting the job done in an appropriate way." This proposition raises the possibility that psychological processes that draw attention to usefulness may enable employees to channel the novel ideas prompted by intrinsic motivation toward creativity.

\section{The Impact of Other-Focused Psychological Processes}

We propose that other-focused psychological processes play an important role in guiding employees toward considering ideas that are not only novel, but also useful. Ideas that are maximally useful are those that are applicable to addressing the problems or needs of a wide range of coworkers, supervisors, customers, and clients (Mohrman et al., 2001). Thus, we expect that when employees focus their attention on others, they will be more likely to develop ideas that are ultimately useful to others. To explain how other-focused psychological processes channel intrinsic motivation toward ideas that are useful as well as novel, we build on motivated information processing theory, according to which employees' desires shape how they attend to information (e.g., Kunda, 1990). We first explain how prosocial motivation encourages employees to attend to information about others' perspectives. We then articulate how this ensuing process of perspective taking, the central cognitive process in our conceptual model, enables intrinsi- cally motivated employees to develop ideas that are useful as well as novel.

The moderating effect of prosocial motivation. Motivated information processing theory suggests that to take others' perspectives and determine what they find useful, employees need to have a desire to do so (Kunda, 1990; see also Caruso, Epley, \& Bazerman, 2006). We propose that prosocial motivation is an other-focused psychological process that directs employees' attention toward others' perspectives on what is useful, enhancing the impact of intrinsic motivation on creativity. Prosocial motivation is the desire to expend effort based on a concern for helping or contributing to other people (Grant, 2007). In contrast with traditional assumptions that prosocial and self-interested motivations involve mutually exclusive or opposing desires (e.g., Batson, 1998; Meglino \& Korsgaard, 2004; Schwartz \& Bardi, 2001), recent research has indicated that prosocial and self-interested motivations are empirically independent and can even be positively related (De Dreu \& Nauta, 2009). This is because prosocial motivation can serve multiple goals. For example, employees can desire to help others because they care about them, because they feel that it is the right thing to do, because they wish to maintain membership in a valued group, and/or because doing so will make them feel good about themselves (Batson, Ahmad, Powell, \& Stocks, 2008). Thus, prosocial motivation can involve, but should not necessarily be equated with, altruism; it refers to a concern for others, not a concern for others at the expense of self-interest (De Dreu, 2006).

Although prosocial motivation can be directed toward different beneficiaries, such as coworkers, supervisors, clients, or customers, research has shown that a more general form of prosocial motivation directed toward benefiting others in one's work context is associated with higher job performance, personal initiative, and organizational citizenship behaviors (De Dreu \& Nauta, 2009). Pro- 
social motivation can thus be understood as a psychological state in which employees are focused on the goal of benefiting other people (Batson, 1998; De Dreu, 2006; Grant, 2007). Prosocial motivation can be distinguished from intrinsic motivation along three dimensions: self-regulation, goal directedness, and temporal focus (Grant, 2008). In terms of self-regulation, intrinsic motivation involves fully autonomous self-regulation, whereas prosocial motivation is based on otheroriented values that can be internalized to varying degrees. In terms of goal directedness and temporal focus, intrinsic motivation involves a primarily task-focused emphasis on the process of completing work in the present, whereas prosocial motivation involves a primarily other-focused emphasis on producing beneficial outcomes in the future.

Why would prosocial motivation enhance the effect of intrinsic motivation on creativity? Prosocial motivation provides employees with the meaningful outcome goal of helping others (Batson, 1998; Grant, 2007). Therefore, in the context of idea generation, prosocially motivated employees will be driven to develop ideas that are useful to the coworkers, supervisors, clients, or customers who benefit from their efforts. Indeed, psychological research suggests that employees with high prosocial motivation are driven to produce ideas that are useful to future generations (McAdams \& de St. Aubin, 1992). As such, prosocial motivation may enable employees to channel their intrinsic motivation toward producing ideas that are not only novel, but also useful to others. Although intrinsic motivation offers positive affect and cognitive flexibility to help employees generate novel ideas, prosocial motivation offers an important other-focused outcome goal to help employees focus on their most useful and relevant ideas. Illustrating this synergy, Simonton (1989) found that classical composers, who typically report high intrinsic motivation for writing music, tend to produce their most creative, aesthetically significant works when they are prosocially motivated to leave behind great final pieces for their audiences. Thus, we predict that prosocial motivation will enhance the impact of intrinsic motivation on creativity.

Hypothesis 1. Prosocial motivation strengthens the association between intrinsic motivation and creativity.

The role of perspective taking. To shed light on the core psychological process underlying this hypothesis, we propose that perspective taking will mediate the moderating effect of prosocial motivation on the relationship between intrinsic motivation and creativity. As depicted in Figure 1, in our

FIGURE 1

Summary of Hypotheses ${ }^{a}$

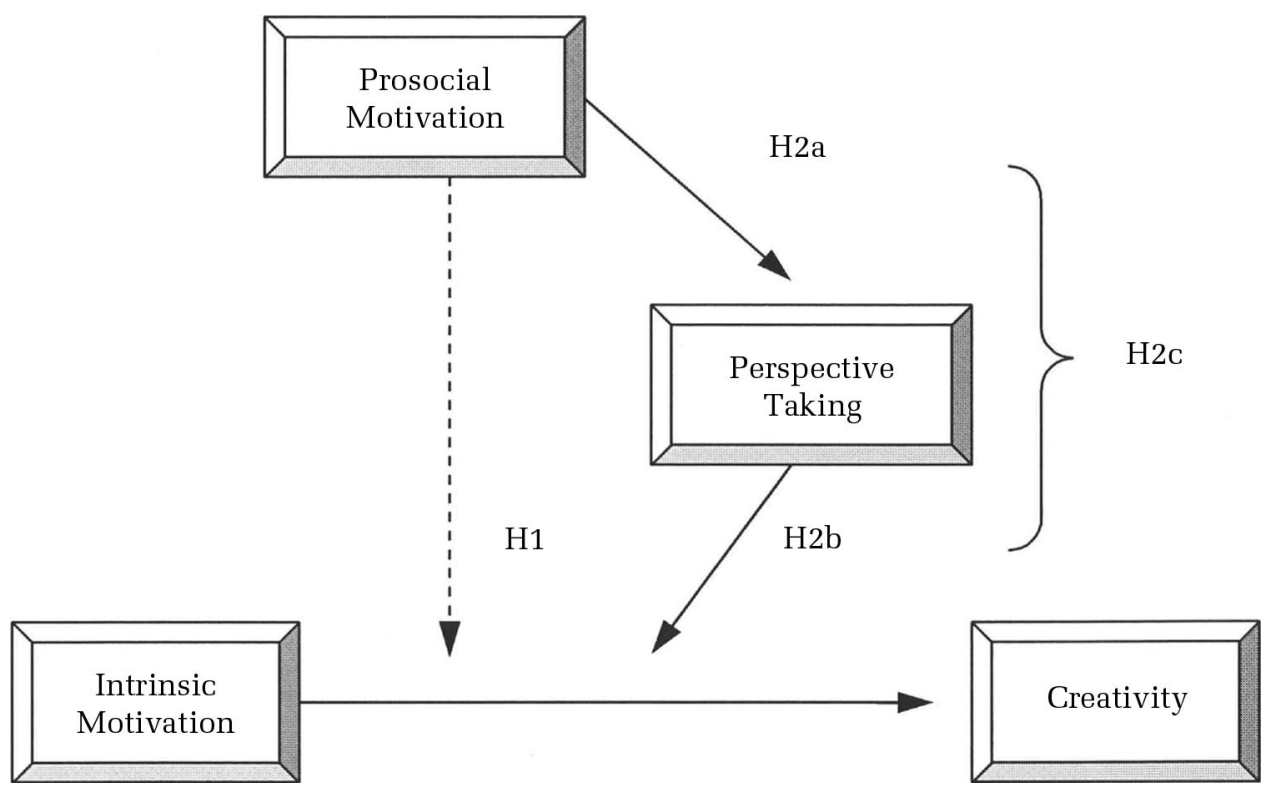

${ }^{a}$ We propose and depict a direct moderating effect of prosocial motivation in keeping with classic and contemporary models of mediation, which suggest that-special cases such as suppression excluded-mediation begins with a direct effect that researchers then seek to explain through one or more intervening variables (Edwards \& Lambert, 2007; Mathieu \& Taylor, 2006). We expect full mediation such that the moderating effect of prosocial motivation is eliminated when perspective taking is incorporated into the model. 
mediated moderation model perspective taking-as driven by prosocial motivation-enhances the effect of intrinsic motivation on creativity. We first explain why prosocial motivation encourages perspective taking and then examine why perspective taking strengthens the impact of intrinsic motivation on creativity.

Perspective taking is a cognitive process in which individuals adopt others' viewpoints in an attempt to understand their preferences, values, and needs (Parker \& Axtell, 2001). Although employees can vary in their dispositional tendencies to take the perspectives of others, research has shown that efforts to take the perspectives of others in specific situations and contexts vary as a function of employees' motivations (e.g., Batson, Early, \& Salvarani, 1997; De Dreu et al., 2000; Galinsky, Magee, Inesi, \& Gruenfeld, 2006). We predict that prosocial motivation will encourage employees to engage in perspective taking. Motivated information processing theory (De Dreu, 2006) provides the conceptual basis for this relationship. Recent advances in motivated information processing research have revealed how prosocial motivation shapes the cues that individuals selectively notice, encode, and retain (De Dreu et al., 2000). When employees are prosocially motivated, their desires to benefit others lead them to pay heightened attention to others' perspectives in order to identify ways to help them effectively (De Dreu et al., 2000). As De Dreu (2006: 1248) explained, prosocial motivation leads employees to "consider information from multiple perspectives to a greater extent ... [and] stimulates the processing of social information-information from and about relevant others."

Indeed, extensive research in both psychology and management has shown that prosocially motivated individuals are more likely to adopt the perspectives of a range of other people, including coworkers, supervisors, suppliers, customers, and clients (Axtell, Parker, Holman, \& Totterdell, 2007; Batson, 1998; De Dreu et al., 2000; Parker \& Axtell, 2001). Because prosocially motivated employees are more aware of, and concerned about, other people's goals and preferences (Meglino \& Korsgaard, 2004), they ask questions, listen carefully, and observe behaviors in order to understand what others value, obtaining cues about how to provide help effectively (De Dreu et al., 2000). Thus, we predict that prosocially motivated employees will be more likely to take others' perspectives.

Hypothesis 2a. Prosocial motivation is positively associated with perspective taking.

We further propose that perspective taking, in turn, will strengthen the effect of intrinsic motiva- tion on creativity. We base this hypothesis on theory and research on creative cognitive processing and motivated information processing. The literature on creative cognitive processing shows that after generating possibilities, employees progress psychologically through phases of testing, validating, and refining different ideas (Amabile \& Mueller, 2007). In these phases, because novel possibilities have already been generated, novelty is less important than converging on ideas that are useful, relevant, and appropriate (Amabile, 1996). To translate novel possibilities into creative ideas, employees need to filter out those that are least useful and retain those that are most useful (Campbell, 1960; Litchfield, 2008; Simonton, 2003). After all, many novel ideas end up being trivial or impractical (Silvia, 2008).

Focusing attention on the perspectives of others will provide employees with a standard for determining which ideas should be selected as useful versus discarded as less useful. According to motivated information processing theory and research, when employees take the perspectives of others, they are more likely to think in an integrative fashion to consolidate and align these perspectives (De Dreu et al., 2000). As employees consider more numerous and diverse perspectives, they gain a deeper understanding of which ideas different groups of beneficiaries, constituents, or stakeholders are most likely to consensually consider useful (Amabile, 1996). Indeed, Mohrman et al. (2001) found that when academic researchers took the perspectives of practitioners, they succeeded in conducting research that practitioners judged as more useful. Furthermore, taking others' perspectives can enable employees to identify useful applications of novel but otherwise impractical ideas. Studies of product development teams have shown that when employees adopt the perspectives of coworkers and customers, they are more capable of translating their novel ideas into useful products (Dougherty, 1992; Purser, Pasmore, \& Tenkasi, 1992).

In summary, theories of creative cognitive processing and motivated information processing suggest that by engaging in perspective taking, employees obtain a clearer, more integrative understanding of what types of ideas will be useful to the coworkers, supervisors, clients, customers, and other stakeholders who evaluate and benefit from their work. Intrinsic motivation provides employees with access to novel ideas, and perspective taking provides them with a filter for determining which of these ideas to develop and how to elaborate them in useful ways (Boland \& Tenkasi, 1995; Dougherty, 1992). For example, when an intrinsi- 
cally motivated product development team member generates novel possibilities, taking a customer's perspective is likely to focus her/his attention and energy on further developing the possibilities that are most useful for solving the customer's problems. As Sethi and Nicholson (2001: 159) explained, awareness of customers' needs "can enhance members' commitment to strive for superior outcomes that can better satisfy" these needs, increasing the probability of creative ideas. We thus expect that perspective taking will enhance the effect of intrinsic motivation on creativity.

Hypothesis 2b. Perspective taking strengthens the association between intrinsic motivation and creativity.

Our preceding two hypotheses propose that prosocial motivation increases perspective taking (Hypothesis 2a) and that perspective taking enhances the effect of intrinsic motivation on creativity (Hypothesis 2b). Together, these two hypotheses predict that perspective taking mediates the moderating effect of prosocial motivation on the relationship between intrinsic motivation and creativity (Hypothesis 1), constituting a case of mediated moderation (Edwards \& Lambert, 2007). Although mediated moderation can take multiple forms, the type of mediated moderation that we expect is present when (1) a variable (prosocial motivation) moderates the relationship between an independent variable (intrinsic motivation) and a dependent variable (creativity), as in Hypothesis 1; (2) the moderating variable (prosocial motivation) causes a mediating variable (perspective taking), as in Hypothesis 2a; and (3) the mediating variable (perspective taking) moderates the relationship between an independent variable (intrinsic motivation) and a dependent variable (creativity), as in Hypothesis 2b, thereby transmitting-and eliminating-the moderating effect of the original moderator (prosocial motivation). Having already proposed these relationships, we present our formal hypothesis for mediated moderation: prosocial motivation strengthens the association between intrinsic motivation and creativity by encouraging perspective taking.

\section{Hypothesis 2c. Perspective taking mediates the} moderating effect of prosocial motivation on the association between intrinsic motivation and creativity.

We tested these hypotheses in three studies. In Study 1, we tested Hypothesis 1 by examining the role of prosocial motivation in moderating the relationship between intrinsic motivation and cre- ativity. In Studies 2 and 3, we tested the full theoretical model depicted in Figure 1.

\section{STUDY 1: METHODS}

\section{Sample and Procedures}

We collected motivation data from 90 security force officers and collected lagged creativity ratings from their supervisors at a military base in the northwestern United States. Of the officers, 77.8 percent were male, and average job tenure for the sample was 3.25 years (s.d. $=4.13$ years). They were responsible for protecting physical security and preventing theft and sabotage. A human resources professional sent an electronic message to all 269 security force officers on the base announcing a collaboration with a research team interested in conducting an academic study of their experiences. The officers were invited to complete a survey online either during or outside of work hours. To protect confidentiality, the survey was hosted on a university server, and participants had the opportunity to identify themselves by code names, which were later matched to their supervisors' ratings by a neutral third party. We received completed surveys from 90 officers, for a response rate of 33.5 percent. Nine months later, we asked their supervisors to evaluate the creativity that they had exhibited since the surveys were completed. We received supervisor ratings for all 90 officers, a 100 percent response rate. With the exception of five supervisors who rated multiple employees, each supervisor rated a single unique employee.

The employees were responsible for monitoring and repairing equipment, coordinating and conducting surveillance activities and patrols, developing contingency plans and disaster protocols, preparing for inspections, and assessing, responding to, and neutralizing security threats. Examples of creative ideas included developing protocols for unforeseen but serious threats, looking for ways to utilize limited staff and resources to cover several thousand square miles of ground, suggesting new contingencies and sources of variability in training procedures and contingency plans, generating dynamic interview protocols for questioning suspects, and finding faster ways to repair equipment.

\section{Measures}

Unless otherwise indicated, all items used a Likert-type scale anchored at 1 ("disagree strongly") and 7 ("agree strongly").

Intrinsic and prosocial motivations. The officers completed the intrinsic and prosocial motivation 
TABLE 2

Study 1: Means, Standard Deviations, and Correlations ${ }^{\mathrm{a}}$

\begin{tabular}{|c|c|c|c|c|c|c|c|c|}
\hline Variable & Mean & s.d. & 1 & 2 & 3 & 4 & 5 & 6 \\
\hline 1. Creativity & 5.52 & 1.13 & $(.97)$ & & & & & \\
\hline 2. Intrinsic motivation & 3.84 & 1.89 & $.32^{* *}$ & $(.94)$ & & & & \\
\hline 3. Prosocial motivation & 5.13 & 1.43 & $.28^{* *}$ & $.55^{* * *}$ & $(.91)$ & & & \\
\hline 4. Autonomy & 4.22 & 1.81 & .07 & $.41^{* * *}$ & $.42^{* * *}$ & $(.97)$ & & \\
\hline 5. Conscientiousness & 5.32 & 1.08 & .06 & .13 & .18 & .15 & $(.75)$ & \\
\hline 6. Openness & 4.87 & 1.03 & .07 & .14 & $.23^{* *}$ & -.09 & .18 & $(.77)$ \\
\hline
\end{tabular}

scales developed by Grant (2008). The scales open with the question, "Why are you motivated to do your work?" and then allow respondents to rate their intrinsic and prosocial motivations. The intrinsic motivation scale is composed of four items, including "Because I enjoy the work itself" and "Because it's fun" ( $\alpha=.94)$. The prosocial motivation scale is also composed of four items, including "Because I want to help others through my work" and "Because I care about benefiting others through my work" $(\alpha=.91){ }^{1}$

Creativity. At the time that the officers completed their surveys, we asked their supervisors to pay attention to each officer's creativity over the subsequent months. Nine months later, we sent a survey to the supervisors asking them to reflect on the preceding nine months and to rate each officer's creativity. The supervisors were blind to the study hypotheses and to officers' survey responses. We selected a nine-month time lag to provide supervisors with adequate opportunity to observe each officer's creative ideas and contributions. The supervisors provided the ratings using the nine-item creativity scale developed by Tierney et al. (1999), which includes items such as "Generates novel, but operable work-related ideas" and "Serves as a good role model for creativity" $(\alpha=.97)$.

Control variables. We controlled for contextual and individual factors that could be expected to influence both motivation and creativity. Since autonomy can facilitate both intrinsic motivation and

\footnotetext{
${ }^{1}$ We introduced this section of the survey by stating that we were interested in employees' workplace relationships, requesting that responses focus on the people directly affected by their jobs. We used the term "others" to allow employees to focus on the direct beneficiaries of their own jobs. At the end of the survey, we included an open-ended question asking participants to indicate which beneficiaries they had in mind. Ninety percent of participants mentioned coworkers and civilians, and the remaining 10 percent mentioned supervisors.
}

creativity (e.g., Elsbach \& Hargadon, 2006), we controlled for this job characteristic, measured with the scale developed by Morgeson and Humphrey (2006). Since conscientiousness and openness may relate to both creativity and intrinsic motivation (e.g., Shalley et al., 2004), we controlled for these two traits, measured with the four-item scales developed by Donnellan, Oswald, Baird, and Lucas (2006).

\section{STUDY 1: RESULTS AND DISCUSSION}

Means, standard deviation, and correlations for the key study variables appear in Table 2 . We began by examining the factor structure of the three focal variables: intrinsic motivation, prosocial motivation, and creativity. We conducted a confirmatory factor analysis using EQS software version 6.1 with maximum-likelihood estimation procedures (e.g., Kline, 1998). The expected three-factor solution displayed excellent fit with the data $\left(\chi^{2}[116]=\right.$ 196.12 , CFI $=.95$, SRMR $=.04$ ). All factor loadings were statistically significant and ranged from .87 to .94 for the intrinsic motivation items, .82 to .90 for the prosocial motivation items, and .84 to .95 for the creativity items. We tested all alternative nested models to examine whether a more parsimonious model achieved equivalent fit (for intrinsic and prosocial motivations on the same factor, $\chi^{2}[118]=$ 346.29 , CFI $=.86$, SRMR $=.09$; for intrinsic motivation and creativity on the same factor, $\chi^{2}[118]=$ 514.11 , CFI $=.76$, SRMR $=.19$; for prosocial motivation and creativity on the same factor, $\chi^{2}[118]=$ $447.92, \mathrm{CFI}=.80, \mathrm{SRMR}=.19$; and for a one-factor model, $\chi^{2}[119]=733.71$, CFI $=.62$, SRMR $=.23$ ). Chi-square difference tests showed that our model achieved significantly better fit.

We then conducted hierarchical ordinary least squares (OLS) regression analyses to test our hypothesis that prosocial motivation would strengthen the association between intrinsic motivation and creativity. We followed the moderated regression 
procedures recommended by Aiken and West (1991), entering the control variables in step 1, intrinsic and prosocial motivations in step 2, and their interaction in step 3 . Table 3 depicts the results of our moderated regression analyses. With respect to our core hypotheses about the relationship of intrinsic and prosocial motivations with creativity, it is worth noting that intrinsic motivation was a significant, independent predictor of creativity, but prosocial motivation was not (step 2). However, as predicted in Hypothesis 1, the partialed product of intrinsic and prosocial motivation was a significant, positive predictor of creativity (step 3). To facilitate the interpretation of the interaction, as Aiken and West (1991) recommended, we plotted the simple slopes for the relationship between intrinsic motivation and creativity at one standard deviation above and below the mean of prosocial motivation. The results, which are plotted in Figure 2, suggest that in keeping with Hypothesis 1 , prosocial motivation strengthened the association between intrinsic motivation and creativity. To test this interpretation, we statistically compared the two slopes to zero. As expected, when prosocial motivation was high, intrinsic motivation significantly predicted higher levels of creativity $(b=.52$, s.e. $=.18, \beta=.46, t=2.84, p<$ .01). When prosocial motivation was low, intrinsic motivation did not predict creativity, as the slope did not differ significantly from zero $(b=.01$, s.e. $=$ $.18, \beta=.01, t=0.04, p=.97$ ).

These results provide initial support for our hypothesis that prosocial motivation strengthens the association between intrinsic motivation and creativity. Officers with high levels of intrinsic motivation were more likely to earn higher supervisor creativity ratings when they also had high levels of prosocial motivation. Although these findings are encouraging in providing initial support for our theoretical prediction, to strengthen our confidence in their validity and generalizability, it was important to conduct a constructive replication with different samples and measures. In addition, we had yet to test our mediating hypotheses about perspective taking as an explanatory mechanism for the moderating role of prosocial motivation, as well as to rule out alternative explanations.

\section{STUDY 2: METHODS}

To address these limitations, our second study used new measures of prosocial motivation and creativity, included perspective taking, and controlled for several alternative explanations.

\section{Sample and Procedures}

We collected data from 111 employees and their direct supervisors at a water treatment plant in the southeastern U.S. We sent e-mails to all $796 \mathrm{em}$ ployees on staff, asking them to participate in a confidential survey about work motivation. We received responses from 209 employees, for a response rate of 26.3 percent. We asked participants to list their supervisors' names and e-mail addresses, and we sent a creativity survey to their

TABLE 3

Study 1: Moderated Regression Analyses Predicting Creativity ${ }^{\text {a, b }}$

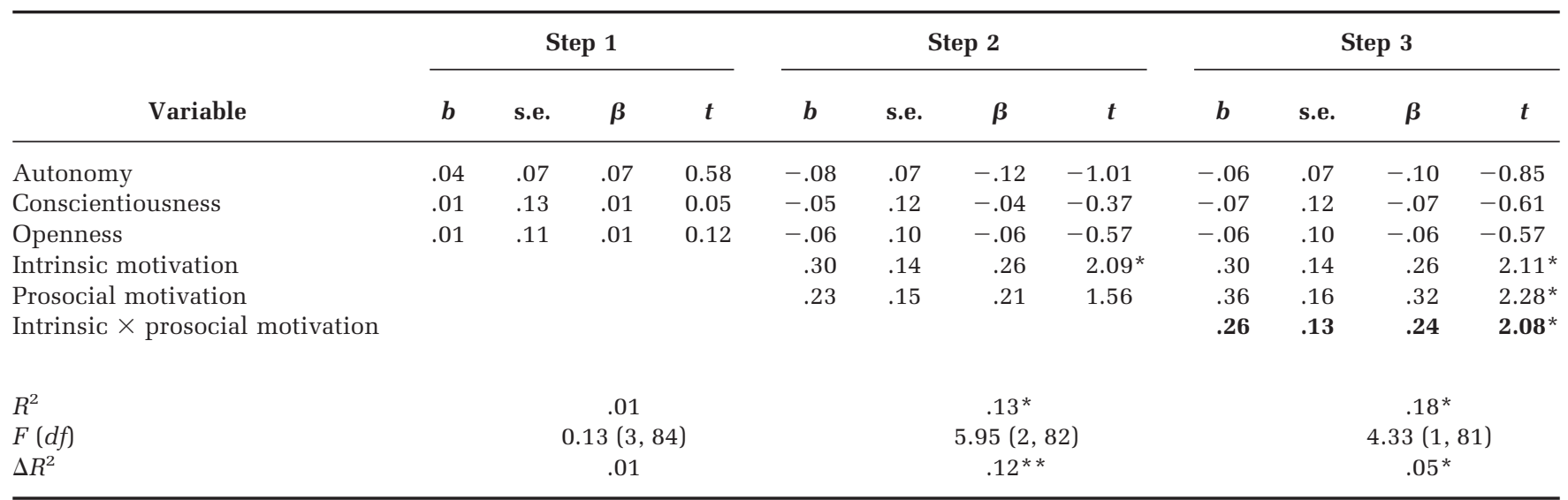

\footnotetext{
${ }^{\mathrm{a}} n=90$. Values in bold are relevant to tests of hypotheses.

${ }^{\mathrm{b}}$ Since there were five supervisors who rated multiple employees, we conducted additional analyses using fixed effects, inserting dummy variables for each supervisor to adjust for dependencies in the data. The interaction between intrinsic and prosocial motivations was still significant $(b=.36$, s.e. $=.13, \beta=.33, t=2.71, p<.01)$. We replicated this pattern of results using random coefficient modeling as well.

${ }^{*} p<.05$

${ }^{* *} p<.01$
} 
FIGURE 2

Study 1: Simple Slopes

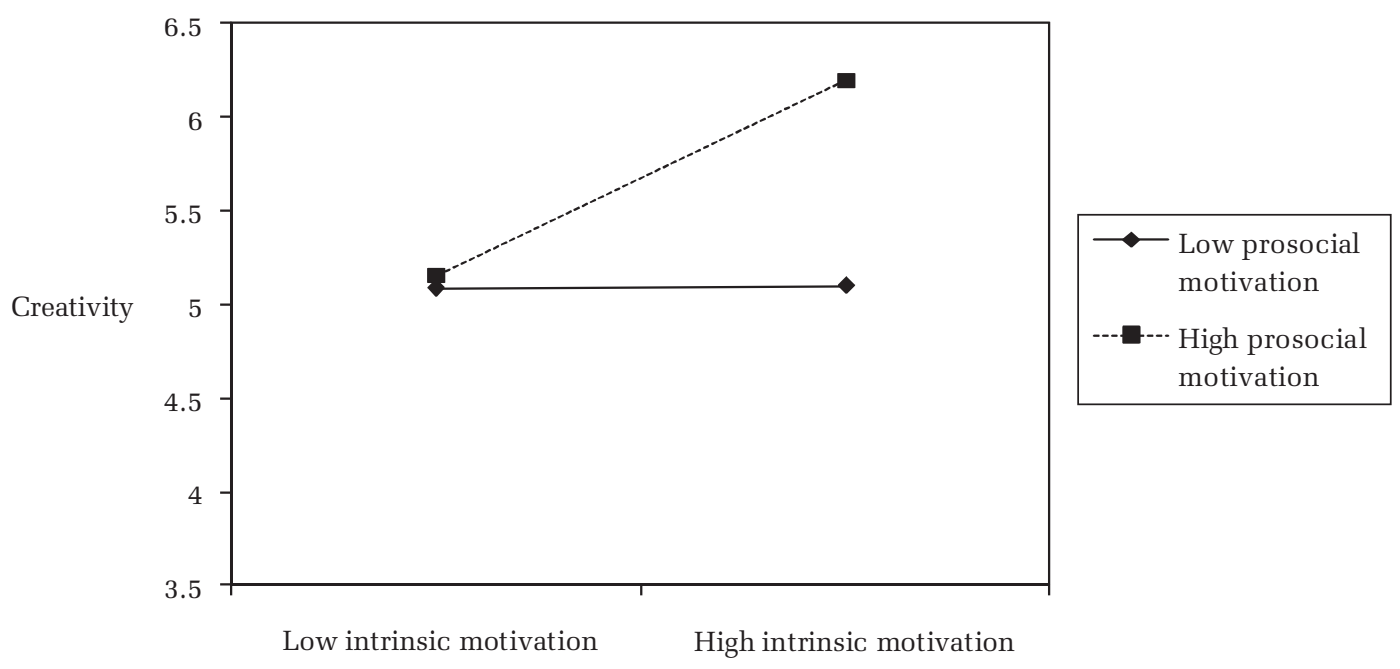

supervisors, asking supervisors to rate only one subordinate. We received 111 unique supervisor responses, representing a response rate of 53.1 percent. For the final data set, we focused on the matched sample of 111 employees and their direct supervisors. Of these employees, 68.5 percent were female, and they averaged 44.1 years of age, 14.0 years of experience in the organization, and 6.47 years in their current jobs. Of the supervisors, 77.5 percent were male, and they averaged 49.1 years of age, 19.0 years of experience in the organization, and 5.1 years supervising the employees. We asked employees to provide ratings of their intrinsic and prosocial motivations, levels of perspective taking, and several control variables and asked supervisors to rate employees' creativity. The employees were responsible for monitoring and repairing equipment, responding to customer questions, updating safety standards, developing and improving engineering procedures, preventing and resolving system problems, reducing pollution, and implementing new testing processes. Examples of creative ideas included developing techniques for preventing equipment failures, proposing new pollution control methods, and suggesting new work processes and safety protocols.

\section{Measures}

Unless otherwise indicated, all measures used a scale anchored at 1 ("disagree strongly") and 7 ("agree strongly").

Intrinsic and prosocial motivations. We measured intrinsic motivation with the same four-item scale (Grant, 2008) as we used in our previous study $(\alpha=.91)$. We measured prosocial motivation using Grant and Sumanth's (2009) five-item scale, which includes items such as "I get energized by working on tasks that have the potential to benefit others" and "I prefer to work on tasks that allow me to have a positive impact on others" $(\alpha=.90)$.

Perspective taking. Because perspective taking is an intrapsychic or internal psychological process of adopting another's viewpoint, it is often not apparent to observers or overtly displayed in everyday behaviors. Thus, in field settings, employees themselves are often in the strongest position to report on their own perspective-taking efforts. Research has demonstrated the reliability and validity of self-reports of perspective taking (e.g., Davis, Conklin, Smith, \& Luce, 1996), which predict supervisor ratings of employee behaviors such as cooperation with team members (Parker \& Axtell, 2001) and helping customers (Axtell et al., 2007). Employees indicated the extent to which they took others' perspectives at work using a four-item scale adapted from the Davis et al. (1996) perspective taking measure. The items were "On the job, I frequently try to take other people's perspectives," "At work, I often imagine how other people are feeling," "On the job, I make an effort to see the world through others' eyes," and "At work, I regularly seek to understand others' viewpoints" $(\alpha=$ $.80) .^{2}$

\footnotetext{
${ }^{2}$ As in Study 1, we asked participants to respond to the prosocial motivation and perspective taking questions in reference to the direct beneficiaries of their jobs. In an open-ended question at the end of the survey, 89 percent of participants mentioned coworkers and community members, and the remaining 11 percent mentioned supervisors.
} 
Creativity. Supervisors provided ratings of employees' creativity using the 13-item creativity scale developed by George and Zhou (2001), which includes "Comes up with new and practical ideas to improve performance" and "Is a good source of creative ideas" $(\alpha=.97)$.

Control variables. From a demographic standpoint, we controlled for sex, job tenure, and marital status. For job characteristics, we controlled for autonomy with the same scale used in Study 1 (Morgeson \& Humphrey, 2006). We also used the Morgeson and Humphrey (2006) scale to measure skill variety, which has been linked to both intrinsic motivation and creativity (e.g., Elsbach \& Hargadon, 2006). For personality traits, we measured conscientiousness and openness using the same scales as in Study 1 (Donnellan et al., 2006). We also controlled for psychological safety, which might enhance both intrinsic motivation and creativity, using Edmondson's (1999) seven-item scale.

To provide a more robust test of the unique moderating role of prosocial motivation, we also controlled for extrinsic motivations. Doing so had the potential to strengthen our results by allowing us to test whether extrinsic motivations, which can also cultivate a focus on outcome goals, may serve the same function as prosocial motivation in enhancing the relationship between intrinsic motivation and creativity. We measured three extrinsic motivations-external, introjected, and identified-using four items for each adapted from Ryan and Connell (1989). As with the intrinsic and prosocial motivation items, we opened with the question, "Why are you motivated to do your work?" The external items were "Because I need to pay my bills," "Because I need to earn money," "Because I have to," and "Because I need the income" $(\alpha=$ .92). The introjected items were "Because I want to avoid feeling guilty," "Because I'll feel bad about myself if I don't," "Because I want to avoid looking bad," and "Because I'll feel ashamed if I don't" $(\alpha=$ .90). The identified items were "Because I think it's important," "Because I don't want to cause harm," "Because it's satisfying," and "Because I want to do a good job” $(\alpha=.80)$.

\section{STUDY 2: RESULTS AND DISCUSSION}

Means, standard deviation, and correlations are displayed in Table 4. We conducted a confirmatory factor analysis to assess the factor structure of the four key variables: intrinsic motivation, prosocial motivation, perspective taking, and creativity. The predicted four-factor solution achieved adequate fit with the data $\left(\chi^{2}[293]=522.54, \mathrm{CFI}=.92\right.$, SRMR $=$ .06). All factor loadings were statistically significant, ranging from .82 to .93 for the intrinsic motivation items, .75 to .90 for the prosocial motivation items, .66 to .83 for the perspective taking items, and .65 to .95 for the creativity items. Plausible alternative models displayed significantly poorer fit. However, the CFI value fell below .95, which might be due to the fact that the creativity scale included a large number of items, constituting an overidentified variable. This can cause parameter instability related to the presence of multiple solutions, correlated residuals and cross-loadings, and increased standard errors, especially in a small sample such as ours (Little, Cunningham, Shahar, \& Widaman, 2002). To adjust for these issues by re-

TABLE 4

Study 2: Means, Standard Deviations, and Correlations ${ }^{\text {a }}$

\begin{tabular}{|c|c|c|c|c|c|c|c|c|c|c|c|c|c|c|c|c|c|}
\hline Variable $^{\text {b }}$ & Mean & s.d. & 1 & 2 & 3 & 4 & 5 & 6 & 7 & 8 & 9 & 10 & 11 & 12 & 13 & 14 & 15 \\
\hline 1. Creativity & 5.49 & 0.98 & $(.97)$ & & & & & & & & & & & & & & \\
\hline 2. Intrinsic motivation & 5.63 & 1.03 & $.21 *$ & $(.91)$ & & & & & & & & & & & & & \\
\hline 3. Prosocial motivation & 5.74 & 0.78 & .10 & $.27 * *$ & $(.90)$ & & & & & & & & & & & & \\
\hline 4. Perspective taking & 5.49 & 0.76 & .02 & .08 & $.28 * *$ & $(.80)$ & & & & & & & & & & & \\
\hline 5. External motivation & 6.25 & 0.85 & -.06 & -.17 & -.02 & .15 & $(.92)$ & & & & & & & & & & \\
\hline 6. Introjected motivation & 5.60 & 0.97 & -.04 & .11 & $.24^{*}$ & $.30 * *$ & -.11 & $(.90)$ & & & & & & & & & \\
\hline 7. Identified motivation & 4.14 & 1.15 & .13 & -.09 & .04 & .05 & $.20^{*}$ & .10 & $(.80)$ & & & & & & & & \\
\hline 8. Sex & 0.32 & 0.47 & -.09 & .03 & .17 & .13 & .08 & .03 & -.12 & - & & & & & & & \\
\hline 9. Job tenure & 6.47 & 7.52 & .05 & -.06 & -.07 & -.15 & .05 & -.04 & -.06 & .16 & - & & & & & & \\
\hline 10. Marital status & 0.77 & 0.42 & .04 & .11 & -.05 & .01 & -.08 & .02 & .00 & .15 & .18 & - & & & & & \\
\hline 11. Autonomy & 5.66 & 0.88 & $.19^{*}$ & $.19^{*}$ & $.22^{*}$ & .13 & -.06 & .16 & -.10 & -.11 & .07 & .08 & $(.87)$ & & & & \\
\hline 12. Skill variety & 6.29 & 0.62 & .15 & $.32 * *$ & $.22^{*}$ & $.22^{*}$ & -.03 & $.22^{*}$ & .02 & -.10 & .03 & .14 & $.43^{* * *}$ & $(.91)$ & & & \\
\hline 13. Psychological safety & 3.99 & 0.52 & .18 & .09 & .12 & .10 & .11 & -.03 & -.09 & -.04 & .00 & -.09 & $.21^{*}$ & .16 & $(.68)$ & & \\
\hline 14. Conscientiousness & 5.45 & 1.01 & .17 & -.07 & $.19^{*}$ & .09 & -.01 & .03 & .07 & .09 & .08 & -.06 & $-.22^{*}$ & -.06 & -.12 & $(.79)$ & \\
\hline 15. Openness & 5.29 & 1.04 & .13 & .15 & .11 & .17 & .09 & .06 & $-.27 * *$ & -.18 & -.12 & -.06 & .13 & $.33^{* * *}$ & $.19^{*}$ & -.11 & $(.78)$ \\
\hline
\end{tabular}

${ }^{\text {a }} n=111$. Coefficient alphas are on the diagonal in parentheses.

b For sex, $0=$ "female," 1 = "male," For marital status, $0=$ "single," 1 = "married."

${ }^{*} p<.05$

${ }^{* *} p<.01$

*** $p<.001$ 
ducing the number of indicators to the more parsimonious three per factor, we aggregated the creativity scale items using parceling techniques. After reducing the 13-item creativity scale to three parcels, the four-factor solution displayed excellent fit $\left(\chi^{2}[98]=146.53\right.$, CFI $=.96$, SRMR $\left.=.06\right)$. This suggested that the relatively low CFI value might be an artifact of sample size and scale length, indicating that the psychometric properties of our variables were acceptable for further investigation.

To test Hypothesis 1, we used the same moderated regression procedures as in Study 1 (Aiken \& West, 1991). Table 5 reports results of these analyses. Even after we included all of the control variables and the interactions of external, introjected, and identified motivations with intrinsic motivation, the results showed that intrinsic and prosocial motivations interacted significantly to predict supervisors' ratings of creativity, accounting for 3 percent additional variance in creativity (see Table 5, Step 1). Simple slopes suggested that as in the prior study, intrinsic motivation was positively related to creativity when prosocial motivation was high, but not when it was low (see Figure 3). Comparing the slopes to zero substantiated this interpretation, as intrinsic motivation significantly predicted higher levels of creativity when prosocial motivation was high $(b=.45$, s.e. $=.14, \beta=.43, t=3.13$, $p<.01)$ but not when it was low $(b=.00$, s.e. $=.13$, $\beta=.00, t=-0.01, p=.99)$. Thus, prosocial motivation once again strengthened the association between intrinsic motivation and creativity.

We then tested Hypotheses 2a and 2b. In support of Hypothesis 2a, prosocial motivation was significantly associated with perspective taking (see Table 5, Perspective Taking). In support of Hypothesis $2 \mathrm{~b}$, a moderated regression analysis showed that perspective taking and intrinsic motivation interacted to predict creativity (see Table 5, Step 2). Simple slopes showed that the form of the moderating effect of perspective taking mirrored the moderating effect for prosocial motivation: intrinsic

TABLE 5

Study 2: Regression Analyses ${ }^{\mathbf{a}, \mathbf{b}}$

\begin{tabular}{|c|c|c|c|c|c|c|c|c|c|c|c|c|}
\hline \multirow[b]{2}{*}{ Variable } & \multicolumn{4}{|c|}{ Perspective Taking } & \multicolumn{4}{|c|}{ Creativity, Step 1} & \multicolumn{4}{|c|}{ Creativity, Step 2} \\
\hline & $\boldsymbol{b}$ & s.e. & $\boldsymbol{\beta}$ & $t$ & $\boldsymbol{b}$ & s.e. & $\boldsymbol{\beta}$ & $t$ & $\boldsymbol{b}$ & s.e. & $\boldsymbol{\beta}$ & $\boldsymbol{t}$ \\
\hline Sex & -.19 & .16 & -.12 & -1.21 & .00 & .20 & .00 & -0.02 & .04 & .20 & .02 & 0.22 \\
\hline Job tenure & -.01 & .01 & -.13 & -1.39 & .01 & .01 & .08 & 0.88 & .01 & .01 & .11 & 1.18 \\
\hline Marital status & .05 & .17 & .03 & 0.29 & .09 & .22 & .04 & 0.41 & -.07 & .22 & -.03 & -0.31 \\
\hline Autonomy & .05 & .09 & .06 & 0.55 & .28 & .11 & .25 & $2.43^{*}$ & .26 & .12 & .24 & $2.21^{*}$ \\
\hline Skill variety & .12 & .15 & .10 & 0.84 & -.18 & .18 & -.11 & -1.00 & -.27 & .18 & -.17 & -1.47 \\
\hline Psychological safety & -.02 & .14 & -.01 & -0.12 & .37 & .17 & .20 & $2.12^{*}$ & .30 & .17 & .17 & 1.73 \\
\hline Conscientiousness & .03 & .07 & .04 & 0.43 & .31 & .09 & .32 & $3.41 * *$ & .34 & .09 & .35 & $3.66^{* * *}$ \\
\hline Openness & .07 & .08 & .09 & 0.84 & .13 & .10 & .14 & 1.30 & .07 & .10 & .07 & 0.69 \\
\hline External motivation & .08 & .08 & .10 & 1.03 & -.03 & .09 & -.03 & -0.32 & .02 & .09 & .02 & 0.24 \\
\hline Introjected motivation & .19 & .07 & .26 & $2.64^{*}$ & -.03 & .09 & -.03 & -0.34 & .00 & .09 & .00 & 0.02 \\
\hline Identified motivation & .02 & .08 & .03 & 0.26 & .17 & .10 & .17 & 1.72 & .12 & .10 & .12 & 1.18 \\
\hline Intrinsic motivation & -.11 & .09 & -.14 & -1.20 & .37 & .11 & .36 & $3.26 * *$ & .43 & .13 & .39 & $3.36 * *$ \\
\hline Prosocial motivation & .18 & .09 & .22 & $2.11^{*}$ & -.09 & .11 & -.09 & -0.90 & .00 & .11 & .00 & -0.02 \\
\hline Intrinsic $\times$ external motivation & .21 & .10 & .24 & $2.09 *$ & -.20 & .13 & -.17 & -1.55 & -.36 & .13 & -.30 & $-2.69 * *$ \\
\hline Intrinsic $\times$ introjected motivation & .05 & .07 & .08 & 0.72 & .08 & .08 & .09 & 0.94 & .05 & .08 & .07 & 0.65 \\
\hline Intrinsic $\times$ identified motivation & -.05 & .08 & -.06 & -0.59 & -.17 & .09 & -.18 & -1.79 & -.13 & .12 & -.12 & -1.14 \\
\hline Intrinsic $\times$ prosocial motivation & .03 & .08 & .04 & 0.40 & .20 & .09 & .19 & $2.06^{*}$ & .13 & .10 & .13 & 1.37 \\
\hline Perspective taking & & & & & & & & & -.07 & .11 & -.07 & -0.65 \\
\hline $\begin{array}{l}\text { Perspective taking } \times \text { intrinsic } \\
\text { motivation }\end{array}$ & & & & & & & & & .32 & .14 & .25 & $2.20^{*}$ \\
\hline$R^{2}$ & \multicolumn{4}{|c|}{$.28^{*}$} & \multicolumn{4}{|c|}{$.34 * *$} & \multicolumn{4}{|c|}{$.38 * *$} \\
\hline$F(d f)$ & \multicolumn{4}{|c|}{$2.07(17,93)$} & \multicolumn{4}{|c|}{$2.56(17,93)$} & \multicolumn{4}{|c|}{$2.44(2,91)$} \\
\hline$\Delta R^{2}$ & \multicolumn{4}{|c|}{$.28^{*}$} & \multicolumn{4}{|c|}{$.34 * *$} & \multicolumn{4}{|c|}{$.04^{*}$} \\
\hline
\end{tabular}

\footnotetext{
${ }^{\text {a }} n=111$. Values in bold are relevant to tests of hypotheses.

${ }^{\mathrm{b}}$ We also conducted an analysis in which we entered the interaction of intrinsic and prosocial motivations in a separate step between

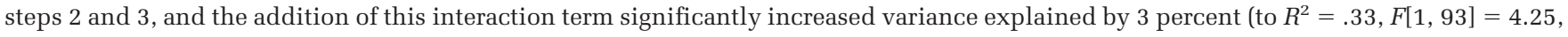
$p=.04)$.

$* p<.05$

${ }^{*} * p<.01$

$* * * p<.001$
} 
FIGURE 3

Study 2: Simple Slopes

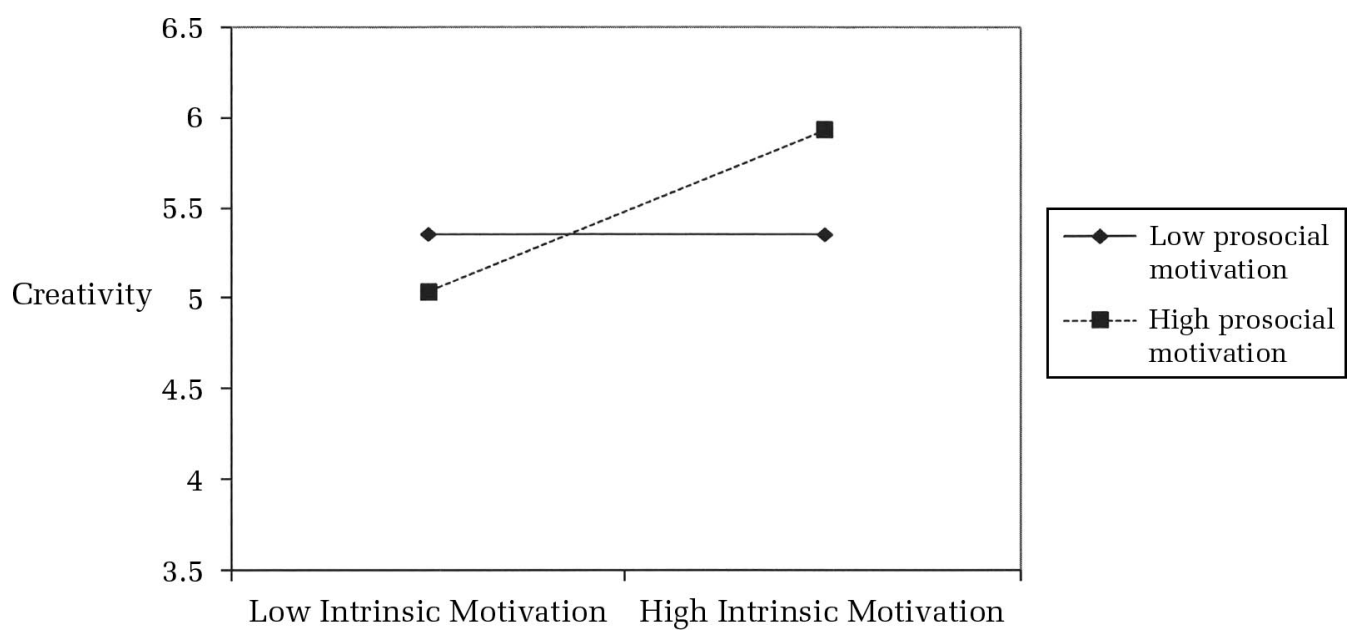

motivation was positively associated with creativity when perspective taking was high $(b=.60$, s.e. $=.19, \beta=.54, t=3.23, p<.01)$ but not when it was low $(b=-.03$, s.e. $=.15, \beta=-.03, t=-0.23$, $p=.82$ ). In this analysis, when we included the moderating effect of perspective taking, the moderating effect of prosocial motivation was reduced to nonsignificance (see Table 5, Steps 1 and 2).

To complete our test of Hypothesis 2c, which predicts that perspective taking mediates the moderating effect of prosocial motivation on the relationship between intrinsic motivation and creativity, we followed the moderated path analysis procedures recommended by Edwards and Lambert (2007). Our previous analyses showed that prosocial motivation predicted perspective taking and that perspective taking moderated the association between intrinsic motivation and creativity, reducing the coefficient for the moderating effect of prosocial motivation. To examine whether accounting for the moderating effect of perspective taking significantly reduced the moderating effect of prosocial motivation, we used a bootstrap procedure. $^{3}$ This procedure allowed us to examine the

\footnotetext{
${ }^{3}$ Our model differs from Edwards and Lambert's (2007) models in that we started with a moderating effect that we sought to explain, rather than starting with a mediated effect that is then moderated at one or two stages. However, the moderated path analysis procedures specified by Edwards and Lambert still applied here; the key difference was that our model involved computing the indirect effect by calculating the reduced-form equation for the product of (1) the path from prosocial motivation to perspective taking and (2) the path for the interaction of perspective taking and intrinsic motivation in predicting creativity.
}

size of the indirect effect of prosocial motivation (in moderating the relationship between intrinsic motivation and creativity) through the mediator of perspective taking. We constructed bias-corrected confidence intervals by drawing 1,000 random samples with replacement from the full sample. An indirect effect is significant when the 95\% confidence interval excludes zero (Edwards \& Lambert, 2007; MacKinnon, Fairchild, \& Fritz, 2007). In our data, the size of the indirect effect from the full sample was .092, and the 95\% confidence interval from the bootstrap analysis excluded zero $(.021, .224)$. These results support Hypothesis 2c, demonstrating that perspective taking mediated the moderating effect of prosocial motivation on the relationship between intrinsic motivation and creativity.

These results constructively replicated and extended our findings from Study 1. We found that prosocial motivation enhanced the relationship between intrinsic motivation and creativity in a new sample with different measures of prosocial motivation and creativity and that perspective taking mediated this moderating effect. Furthermore, the moderating effect of prosocial motivation held even after we controlled for external, introjected, and identified motivations, their interactions with intrinsic motivation, and several possible common causes of intrinsic motivation and creativity. However, these results are subject to at least two key limitations. First, both of our studies relied on correlational designs and used the same measure of intrinsic motivation, making them vulnerable to alternative explanations. To strengthen causal inferences, it was important to use an experimental design with a different operationalization of intrinsic motivation. 
Second, in both studies, we relied on supervisor ratings of creativity, which are vulnerable to a number of weaknesses (e.g., Shalley et al., 2004). For example, supervisors do not always have the opportunity to observe employees' creativity in situ; supervisors are not always experts in the product and service domains in which employees are expected to be creative; and supervisor ratings are often skewed by halo effects, affective cues, and other informationprocessing and decision-making biases that influence appraisals. For example, it is possible that supervisors are biased toward seeing employees with high intrinsic and prosocial motivations-who express high task interest and a concern for contributing to other people and the organization-in a more favorable light. To overcome these limitations and rule out such alternative explanations, we conducted a study in which we used independent ratings of actual ideas that were separated from the individuals who generated them.

\section{STUDY 3: METHODS}

To strengthen causal inferences and rule out alternative explanations, we conducted a laboratory experiment in which participants generated creative ideas to solve a business problem. We independently manipulated intrinsic and prosocial motivations, and we measured perspective taking as a mediator. To prevent supervisor biases from influencing creativity ratings, we asked independent raters to evaluate the creative ideas generated by participants. The raters were blind to all characteristics of the individual participants, as well as to the study's design, manipulations, and hypotheses. In addition, Study 2 only provided correlational evidence linking prosocial motivation to perspective taking. Directly manipulating prosocial motivation in this study allowed us to rule out the possibility that omitted knowledge, skill, and ability variables-important influences on creativity (Amabile \& Mueller, 2007)—were responsible for the results. For example, emotional intelligence may influence both prosocial motivation (e.g., Côté \& Miners, 2006) and perspective taking (Schutte et al., 2001). By randomly assigning participants to experience different levels of prosocial motivation, we could test whether prosocial motivation directly increases perspective taking.

\section{Sample, Design, and Procedures}

We conducted an experiment with 100 undergraduates at a large public U.S. university. Sixty percent of the participants were female, and they completed the study via computer. We recruited them from a university mailing list in exchange for a $\$ 10$ gift certificate to Amazon.com. The experiment used a two-by-two (intrinsic motivation, low/ high, by prosocial motivation, low/high) betweensubjects factorial design. We introduced the study by explaining that we were interested in studying how people solve business problems. We informed participants that they would have a chance to solve a problem that a local organization was facing, and online software randomly assigned them to one of the four experimental conditions using a random number generator. At that point, we introduced our manipulations of intrinsic and prosocial motivations.

Intrinsic motivation manipulation. Psychologists typically manipulate intrinsic motivation by varying the interest level of a task and/or the amount of free choice that individuals are provided in completing the task (Deci, Koestner, \& Ryan, 1999). To ensure that participants in the low and high intrinsic motivation conditions would experience different levels of intrinsic motivation, our manipulation featured a combination of task interest and task choice. We gave participants in the high intrinsic motivation condition a choice between two tasks and accepted their choice of the task described as "interesting," supporting the experience of self-determination. For the low intrinsic motivation condition, we gave participants the same choice but then rejected their selection and required them to perform the task described as "boring," undermining the experience of self-determination. In actuality, all participants performed the same task; the key difference was that participants in the high intrinsic motivation condition were allowed to choose a task framed as interesting, while participants in the low intrinsic motivation condition were prevented from realizing their choices by the requirement to perform a task framed as boring. To set the stage for the manipulations, we provided participants in both conditions with the following overview:

We are conducting two different studies with local bands, and we have received feedback that instead of assigning you randomly to one of the studies, participants like to have a choice. To inform your decision, we have asked past participants to rank how interesting each study was. Accordingly, please choose one of the two tasks below:

(a) A music study that has been rated by participants as extremely interesting, with average ratings of 6.73 on a 7-point "fun" scale

(b) A recording study that has been rated by participants as relatively boring, with average ratings of 2.3 on a 7 -point "fun" scale 
We chose these labels of "music study" and "recording study" because the ensuing task could be interpreted as either one, and we wanted to guide all participants to select the "interesting" study. Indeed, all participants selected the first study, which took them to the next screen on their computers. At this point, we introduced the intrinsic motivation manipulation.

For those in the high intrinsic motivation condition, the screen read, "Thank you for selecting the music study," and provided the instructions for the task. This allowed participants to believe that they would be completing the interesting study that they had chosen, signaling high levels of both task interest and free choice. In the low intrinsic motivation condition, the screen read, "Unfortunately, the music study that you chose is full. We will need you to participate in the recording study." This led participants to believe that they would be completing the boring study that they did not choose, signaling low levels of both task interest and free choice. We believe that the free choice manipulation has greater ecological validity for organizational settings, as there is ample evidence that giving employees choices can achieve long-term increases in intrinsic motivation (e.g., Hackman, Pearce, \& Wolfe, 1978). In contrast, task-framing effects are typically short-lived because employees' actual task experiences tend to override frames (e.g., Zalesny \& Ford, 1990). Nevertheless, in light of evidence that describing a task as interesting can temporarily increase intrinsic motivation in the laboratory (e.g., Glynn, 1994; Zalesny \& Ford, 1990), the task-framing cues were a potentially effective reinforcement of intrinsic motivation.

Prosocial motivation manipulation. For all conditions, we then informed participants that they would be asked to generate ideas to increase a local band's revenues. Psychologists typically manipulate prosocial motivation by varying the level of need that a task beneficiary or recipient expresses, which cultivates empathic concern and thus a desire to help the beneficiary or recipient (Batson, 1998). Accordingly, we provided participants with different information about the level of need that the band members were experiencing. In the high prosocial motivation condition, participants read a statement that the band members were in dire straits:

We have been approached by a local band, the File Drawers, for help with generating ideas for increasing their revenues. In the last three years, the File Drawers have seen their CD sales drop by $92 \%$. All six members of the band have families to feed, and they are in dire straits; on a weekly basis, they are struggling to make ends meet. As Bryan Strickland, the lead singer, told us, "It used to be that we made our profits on CD sales, which have tanked. On our current profits, I can hardly support myself, let alone my family. Our regional popularity has taken off, and I think we're on the verge of success if we can only stay profitable for the next four months while we're writing and recording new songs. I really need your help in coming up with new ideas for bringing in revenue and publicizing our music. I'll do whatever it takes."

In the low prosocial motivation condition, the band members were not in need:

A local band, the File Drawers, is looking to generate ideas for increasing their revenues. In the last three years, the File Drawers have seen their CD sales drop by $7 \%$. All six members of the band are financially secure with successful careers in business and law, but the band is a hobby that they find enjoyable and would like to continue. As Bryan Strickland, the lead singer, told us, "It used to be that we sold a lot of CDs, but now we're looking for additional ways to get our music out there."

Participants in all conditions were asked to generate ideas for how the band could increase revenues. We informed them that we would send their suggestions to the band at the end of the month. After they had generated their ideas, they completed a questionnaire that included a measure of perspective taking and manipulation checks. We then recruited two independent experts to rate the creativity of the ideas that the participants generated.

\section{Measures}

Unless otherwise indicated, all items used the same scale anchors as in the previous studies ( $1=$ "disagree strongly," and 7 = "agree strongly").

Creativity. We recruited two independent experts to rate the creativity of participants' ideas. One of the raters had created and sold music CDs while playing in a band for four years, the other had gained experience with the music industry while working as a business consultant for three years, and both had completed extensive coursework in organizational behavior. They also refreshed their knowledge of the music industry by conducting research on strategies that bands and record companies use to market acts and sell music. We provided them with each participant's ideas in a spreadsheet, stripped of all identifying information. The only information that we offered about the study was that we had asked participants to provide ideas for how a local band could generate revenues and were interested in the raters' assessments of the creativity of each participant's ideas. 
Following Amabile's (1996) consensual assessment technique, we explicitly defined creative ideas as those that are both novel and useful, and we asked the raters to evaluate the ideas on a scale anchored at 1, "not at all creative"; 4, "somewhat creative"; and 7 "very creative." Since the two raters achieved good reliability (ICC2 $=.69, p<.001$ ), and agreement (average deviation $=.63$ ) - well within conventional guidelines (LeBreton \& Senter, 2008)we averaged their ratings into a measure of the overall creativity of each participant's ideas.

Examples of ideas rated as highly creative included producing free music for video games in exchange for publicity; playing concerts for charity or a college homecoming football game; creating a behind-the-scenes YouTube video to generate interest in the band, along with blog and Twitter entries; hiring business students for volunteer marketing internship positions; and building the band's brand image by offering free music lessons, a day with the lead singer, a chance to visit with the band backstage or perform with the band onstage, or an opportunity to write a song for the band. Ideas rated as less creative included eliminating CD sales; performing more concerts in bars and restaurants; selling individual songs on iTunes; selling band merchandise such as T-shirts; doing radio promotions; providing free music downloads on a website; and advertising in newspapers, on websites, and on bulletin boards.

Perspective taking. Participants completed a task-specific measure of perspective taking using four items adapted from the perspective taking scale developed by Davis et al. (1996). The items asked participants to indicate the extent to which they tried to see the band members' perspectives: "I made an effort to see the world through the band members' eyes," "I imagined how the band members were feeling," "I sought to understand the band members' viewpoints," and "I tried to take the band members' perspectives” ( $\alpha=.89)$.
Manipulation checks and control variables. To ensure that our manipulations were effective, we asked participants to complete scales measuring their levels of intrinsic and prosocial motivation in the task. For intrinsic motivation, since our manipulation varied both task interest and free choice, we measured both constructs. As Deci et al. (1999: 655) stated, "The best way to ensure one is assessing intrinsic motivation is to measure both free-choice ... and self-reported interest and to consider them intrinsic motivation only when they correlate within conditions or studies." We measured task interest with the seven-item interest/enjoyment scale developed by Ryan, Koestner, and Deci (1991), which includes items such as "I enjoyed doing this task very much" and "This task was fun to do" $(\alpha=.94)$. We measured perceptions of free choice with the Ryan et al. (1991) seven-item perceived choice scale, which includes items such as "I did this activity because I wanted to" and "I believe I had some choice about doing this activity" $(\alpha=.91)$. We measured prosocial motivation with four items adapted from Grant's (2008) prosocial motivation scale in such a way that they focused specifically on the task: "I wanted to have a positive impact on the band members," "I wanted to help the band members," "I was focused on benefiting the band members," and "I was trying to make the band members better off" $(\alpha=.70)$. Finally, to rule out the possibility that knowledge relevant to the problem influenced the results, we controlled for two sources of experience: whether participants had ever worked in the music industry and whether they had ever earned money through music.

\section{STUDY 3: RESULTS AND DISCUSSION}

Means and standard deviations for each condition appear in Table 6. A multivariate analysis of variance (MANOVA) showed the expected main

TABLE 6

Study 3: Means and Standard Deviations by Condition ${ }^{a}$

\begin{tabular}{|c|c|c|c|c|c|}
\hline Condition & Creativity & $\begin{array}{l}\text { Perspective } \\
\text { Taking }\end{array}$ & $\begin{array}{l}\text { Perceived } \\
\text { Choice }\end{array}$ & $\begin{array}{c}\text { Task } \\
\text { Interest }\end{array}$ & $\begin{array}{c}\text { Prosocial } \\
\text { Motivation }\end{array}$ \\
\hline $\begin{array}{l}\text { Low intrinsic motivation, low prosocial } \\
\text { motivation }(n=25)\end{array}$ & $4.04(1.03)$ & 4.19 (1.24) & $5.51(1.45)$ & $3.43(1.33)$ & $3.96(1.04)$ \\
\hline $\begin{array}{l}\text { Low intrinsic motivation, high prosocial } \\
\text { motivation }(n=22)\end{array}$ & $4.11(1.55)$ & $4.76(1.24)$ & $5.13(1.51)$ & $3.75(1.15)$ & $4.68(0.95)$ \\
\hline $\begin{array}{l}\text { High intrinsic motivation, low prosocial } \\
\text { motivation }(n=26)\end{array}$ & $3.81(1.11)$ & $4.58(0.71)$ & $6.01(0.96)$ & $3.95(1.00)$ & $4.46(0.68)$ \\
\hline
\end{tabular}

a Standard deviations are in parentheses. 
effects of the intrinsic motivation manipulation on perceived choice $(F[1,96]=6.23, p=.01)$ and task interest $(F[1,96]=8.28, p<.01)$ as well as the expected main effects of the prosocial motivation manipulation on self-reports of prosocial motivation $(F[1,96]=9.94, p<.01)$. No other effects were significant. Turning to creativity as the dependent variable, in support of Hypothesis 1, the MANOVA also showed a significant interaction effect of the intrinsic and prosocial motivation manipulations on creativity $(F[1,96]=4.78, p=$ .03). The interaction was robust even after we controlled for the two knowledge variables $(F[1$, $94]=4.50, p=.04)$. Simple effects showed that intrinsic motivation increased creativity when prosocial motivation was high $(F[1,96]=6.70, p$ $=.01$ ), but not when prosocial motivation was low $(F[1,96]=.50, p=.48)$.

Turning to perspective taking, in support of Hypothesis 2a, the MANOVA showed a significant effect of the prosocial motivation manipulation on perspective taking $(F[1,96]=6.03, p=.02)$. The effect was stronger after the two knowledge variables were controlled for $(F[1,94]=6.58, p=.01)$, and no other effects were significant. To test Hypothesis 2b, we used the Aiken and West (1991) moderated regression procedures to examine whether participants' reports of perspective taking moderated the effect of the intrinsic motivation manipulation on creativity. Table 7 presents these results. Supporting Hypothesis 2b, perspective taking interacted positively with the intrinsic motivation manipulation to predict higher creativity (see
Table 7, column 3). In this analysis, when we added the moderating effect of perspective taking, the moderating effect of prosocial motivation was reduced to nonsignificance (see Table 7 , columns 2 and 3).

These analyses established the moderating effect of prosocial motivation on the relationship between intrinsic motivation and creativity, the effect of prosocial motivation on perspective taking, and the moderating effect of perspective taking on the relationship between intrinsic motivation and creativity. We then examined whether perspective taking mediated the moderating effect of prosocial motivation on the relationship between intrinsic motivation and creativity, using the procedures recommended by Edwards and Lambert (2007). Drawing 1,000 random samples using replacement from the full sample, we constructed bias-corrected confidence intervals for the indirect moderating effect of prosocial motivation through the mediator of perspective taking. The indirect effect from the full sample was .29. In keeping with Hypothesis 2c, the $95 \%$ confidence interval from the bootstrap analysis excluded zero $(.052, .730)$. These results support Hypothesis 2c, showing that perspective taking mediated the moderating effect of prosocial motivation on the association between intrinsic motivation and creativity. This evidence constructively replicates our findings that prosocial motivation enhances the effect of intrinsic motivation on creativity, and the experimental manipulations facilitate stronger causal inferences than our prior studies allowed.

TABLE 7

Study 3: Mediated Moderation Analysis ${ }^{a, b}$

\begin{tabular}{|c|c|c|c|c|c|c|c|c|c|c|c|c|}
\hline \multirow[b]{2}{*}{ Variables } & \multicolumn{4}{|c|}{ Perspective Taking } & \multicolumn{4}{|c|}{ Creativity (Step 1) } & \multicolumn{4}{|c|}{ Creativity (Step 2) } \\
\hline & $b$ & s.e. & $\boldsymbol{\beta}$ & $\mathbf{t}$ & $\boldsymbol{b}$ & s.e. & $\boldsymbol{\beta}$ & $t$ & $\boldsymbol{b}$ & s.e. & $\boldsymbol{\beta}$ & $t$ \\
\hline Knowledge control 2 & 0.31 & .69 & .05 & 0.45 & -0.07 & .86 & -.01 & -0.08 & -0.17 & .82 & -.02 & -0.20 \\
\hline Intrinsic motivation & 0.40 & .28 & .20 & 1.42 & -0.23 & .35 & -.09 & -0.67 & -0.25 & .34 & -.10 & -0.73 \\
\hline Prosocial motivation & 0.61 & .30 & .30 & $2.05 *$ & 0.12 & .37 & .05 & 0.33 & 0.03 & .36 & .01 & 0.08 \\
\hline Perspective taking $\times$ intrinsic motivation & & & & & & & & & 0.55 & .27 & .24 & 2.07 * \\
\hline$R^{2}$ & & & .09 & & & & .13 & & & & $.22^{*}$ & \\
\hline$F(d f)$ & & & $1.90(5$ & 94) & & & $2.88(5$ & 94) & & & $5.23 * *($ & 2, 92) \\
\hline$\Delta R^{2}$ & & & .09 & & & & .13 & & & & $.09^{*}$ & \\
\hline
\end{tabular}

a In predicting perspective-taking, when we entered prosocial motivation in a separate step, variance explained increased significantly by 4 percent $(F[1,94]=4.22, p=.04)$.

${ }^{\mathrm{b}}$ Values in bold are relevant to tests of hypotheses.

${ }^{*} p<.05$

$* * p<.01$ 


\section{GENERAL DISCUSSION}

In three studies, we tested the hypothesis that the relationship between intrinsic motivation and creativity is moderated by other-focused psychological processes. The studies provide convergent evidence in support of this hypothesis, revealing that perspective taking, as generated by prosocial motivation, strengthens the association between intrinsic motivation and creativity. The use of multisource measures in three distinct samples-with lagged creativity data in Study 1, multiple motivations controlled in Study 2, and experimental data with independent expert ratings in Study 3 -strengthens the validity of our conclusions.

\section{Theoretical Contributions}

Our research takes a step toward resolving the controversy about the link between intrinsic motivation and creativity. We proposed and found that this relationship is contingent on other-focused psychological processes: intrinsic motivation is most likely to be associated with higher levels of creativity when employees are also prosocially motivated to take the perspectives of others. Studies have begun to identify contextual moderators of the relationship between intrinsic motivation and creativity, such as task complexity (Gagné \& Deci, 2005) and leader-member exchange relationships (Tierney et al., 1999), both of which are thought to stimulate the creativity of intrinsically motivated employees by providing them with challenges and freedom from constraints. However, little research has addressed the possibility that other psychological processes may moderate this relationship.

Our studies demonstrate that perspective taking is an other-focused psychological process that strengthens the relationship between intrinsic motivation and creativity. Psychologists have recognized that perspective taking can directly enhance creativity by providing access to new ideas (e.g., Galinsky, Maddux, Gilin, \& White, 2008), and organizational scholars have found that perspective taking increases the usefulness of ideas (Mohrman et al., 2001). However, neither group has developed or tested theory on the role of perspective taking in moderating the association between intrinsic motivation and creativity. Our emphasis on perspective taking answers recent calls to identify moderators of the relationship between intrinsic motivation and creativity (George, 2007; Shalley et al., 2004). We also introduce perspective taking as a new mechanism for explaining the moderating effects of prosocial motivation on the relationship between intrinsic motivation and creativity.
In doing so, our research presents a new relational view of creativity. A number of researchers have studied how structural and behavioral dimensions of interpersonal relationships, such as social networks (e.g., Perry-Smith, 2006; Perry-Smith \& Shalley, 2003) and communication styles (e.g., Amabile, 1979; Koestner et al., 1984; Shalley \& Perry-Smith, 2001), influence creativity. Our research complements these structural and behavioral approaches by documenting the importance of the psychological dimensions of interpersonal relationships in fueling creativity.

Interestingly, several studies have suggested that other-focused psychological processes can constrain creativity by fostering a focus on conformity, which reduces employees' capability and motivation to think divergently. For example, Goncalo and Staw (2006) found that other-focused values emphasizing collectivism are associated with lower creativity in groups. In contrast, we found evidence that different other-focused psychological processes-prosocial motivation and perspective takingare associated with higher creativity. These findings may be explained by attending to how collectivism differs from prosocial motivation and perspective taking. Collectivism is rooted in conformity values emphasizing the importance of meeting others' expectations and maintaining harmony, which can encourage employees to suppress creative thoughts and unique ideas (Goncalo \& Staw, 2006). On the other hand, prosocial motivation is rooted in values of benevolence and universalism emphasizing the importance of benefiting others (Grant, 2008; Schwartz \& Bardi, 2001), which can encourage employees to think creatively about others' perspectives and identify new strategies for helping them (De Dreu et al., 2000; Parker \& Axtell, 2001). Our research thereby suggests that different other-focused psychological processes may have contrasting effects on creativity.

Finally, our research deepens knowledge about the interaction of intrinsic and prosocial motivations, addressing calls to explore how multiple motivations interact to influence creativity (Amabile, 1996; Eisenberger \& Aselage, 2009; George, 2007). Although research has shown that intrinsic and prosocial motivations interact to predict higher persistence, performance, and productivity (Grant, 2008), these behaviors emphasize "working hard" in completing assigned tasks; creativity, however, is more concerned with "working smart" in introducing novel, useful ideas (e.g., Simonton, 2003). In extending the interaction to creativity, our research fills a gap in existing research about the underlying mechanisms (Grant, 2008), introducing perspective taking and a focus on usefulness as 
new explanatory processes. In addition, from an empirical standpoint, our third study improves upon previous correlational evidence by providing a more rigorous causal examination of the interactive effects of these two motivations.

\section{Limitations and Future Directions}

These contributions should be qualified in light of several limitations. We did not directly test whether intrinsic motivation encourages a focus on novelty, while prosocial motivation and perspective taking draw attention to usefulness. Researchers could conduct such a direct test by obtaining independent assessments of the novelty and usefulness of ideas generated (e.g., Ford \& Gioia, 2000). Also, our research raises important unanswered questions about the boundary conditions for the moderating effects of prosocial motivation and perspective taking. First, prosocial motivation and perspective taking may be directed toward beneficiaries whose viewpoints and values are inconsistent with organizational goals. Our third study created alignment between prosocial motivation toward a band and the task of generating creative ideas to help the band, but prosocial motivation is not always aligned with employees' tasks. It is possible for employees' prosocial motivation and perspective taking to be directed toward targets whose needs are misaligned with those of their organization, a situation that has the potential to reduce creativity by undermining usefulness. For instance, if employees are prosocially motivated to help demanding customers, they may focus on these customers' perspectives at the expense of the organization's needs (e.g., Brief \& Motowidlo, 1986). In addition, inconsistencies may arise when prosocial motivation and perspective taking are narrowly directed toward one beneficiary, which may cause the ideas generated to be less useful to other beneficiaries.

Second, the benefits of prosocial motivation and perspective taking may be circumscribed to situations in which beneficiaries hold different viewpoints from employees. We argued that perspective taking can strengthen the impact of intrinsic motivation simply by encouraging employees to attend to usefulness as well as novelty. However, research has shown that perspective taking can also provide employees with access to viewpoints that provide new information (Galinsky et al., 2008), which might enable them to make more accurate judgments of usefulness. When beneficiaries are psychologically similar-holding comparable knowledge bases, needs, or values-perspective taking may contribute redundant information about what is useful. Third, prosocial motivation may fail to have the proposed moderating effects when individuals are working on creative problems that have low task significance or fail to provide contact with beneficiaries. When the significance of a creative task is low, employees may not channel their prosocial motivation toward the specific creative problem, reserving it for other tasks that have greater impact on others (Grant, Campbell, Chen, Cottone, Lapedis, \& Lee, 2007). When contact with beneficiaries is low, employees may engage in ineffective perspective taking, as it is difficult to understand the viewpoint of anonymous beneficiaries (Parker \& Axtell, 2001).

Researchers should also examine whether there are mechanisms other than prosocial motivation, such as setting goals for helping others, that can foster perspective taking and thus enhance the effect of intrinsic motivation on creativity even in the absence of prosocial motivation. On the one hand, research on both goal setting (Latham, Erez, \& Locke, 1988) and intrinsic motivation (Gagné \& Deci, 2005) has shown that for employees to initiate and sustain effective behavior directed toward a goal, it is important for them to accept and internalize the goal. In view of this evidence, we expect that for helping goals to be successful, they should operate by cultivating prosocial motivation. On the other hand, theories of motivational synergy (Amabile, 1996) suggest that if organizations provide rewards for helping goals that support feelings of autonomy, competence, and relatedness (and thus do not threaten intrinsic motivation), it may be possible for helping goals to foster perspective taking and a focus on usefulness in the absence of prosocial motivation. We hope to see future research address these intriguing questions about external influences on prosocial motivation and perspective taking.

In focusing on motivation, we overlooked key omitted variables, especially skills and abilities (e.g., Amabile \& Mueller, 2007; Simonton, 2003). It may be the case, for example, that high emotional intelligence provides employees with the ability to take others' perspectives more effectively (e.g., Côté \& Miners, 2006). We also did not capture the full range of motivational processes that may be relevant; for instance, our external motivation items focused on economic need, but we did not measure other reasons underlying external motivation, such as the desire to earn money, gain recognition, or earn promotions. Future research should examine whether these external motivations have distinct effects on creativity. Finally, although organizational scholars typically define creativity in terms of novelty and usefulness, psychologists see useful- 
ness as one representation of the broader category of appropriateness (Amabile, 1996). It remains to be seen whether our findings extend to domains such as the natural sciences, literature, and the arts, where appropriateness may be more relevant than usefulness for evaluating creativity.

\section{Practical Implications}

Our research offers important practical implications for organizations and their employees. Managers typically seek to stimulate creativity by creating conditions that are conducive to intrinsic motivation, such as designing challenging and complex tasks, providing autonomy, and developing supportive feedback and evaluation systems. Our research suggests that these practices run the risk of enhancing intrinsic motivation without also cultivating the prosocial motivation and perspective taking that can facilitate the production of ideas that are creative in context. As such, we propose that managers interested in fueling creativity will find it advantageous to create conditions that support prosocial motivation and perspective taking. For example, managers may directly introduce opportunities for perspective taking between employees and their clients or suppliers (Parker \& Axtell, 2001), structure opportunities for employees to interact with the beneficiaries or end users of their work (Grant, 2007), or communicate the urgency of customers' and coworkers' problems. These conditions can enhance prosocial motivation and perspective taking by enabling employees to empathize with others' needs and become more aware of the difference that their ideas can make in others' lives.

\section{Conclusion}

Our research identifies prosocial motivation and perspective taking as important contingencies that strengthen the effects of intrinsic motivation on creativity. Our studies help to resolve theoretical controversies about whether intrinsic motivation influences creativity and provide empirical and practical insights into how multiple motivational processes can drive creativity. As R. Buckminster Fuller, the highly creative inventor, engineer, mathematician, poet, and architect who pioneered the geodesic dome and was known as the da Vinci of the 20th century, said: "The larger the number for whom I worked, the more positively effective I became. Thus, it is obvious that if I worked always ... for all humanity, I would be optimally effective" (Fuller \& Kuromiya, 1981: 125).

\section{REFERENCES}

Aiken, L. S., \& West, S. G. 1991. Multiple regression: Testing and interpreting interactions. Newbury Park, CA: Sage.

Amabile, T. M. 1979. Effects of external evaluation on artistic creativity. Journal of Personality and Social Psychology, 37: 221-233.

Amabile, T. M. 1985. Motivation and creativity: Effects of motivational orientation on creative writers. Journal of Personality and Social Psychology, 48: 393-399.

Amabile, T. M. 1996. Creativity in context. Boulder, CO: Westview Press.

Amabile, T. M., Barsade, S. G., Mueller, J. S., \& Staw, B. M. 2005. Affect and creativity at work. Administrative Science Quarterly, 50: 367-403.

Amabile, T. M., Hennessey, B. A., \& Grossman, B. S. 1986. Social influences on creativity: The effects of contracted-for reward. Journal of Personality and Social Psychology, 50: 14-23.

Amabile, T. M., Hill, K. G., Hennessey, B. A., \& Tighe, E. M. 1994. The Work Preference Inventory: Assessing intrinsic and extrinsic motivational orientations. Journal of Personality and Social Psychology, 66: 950-967.

Amabile, T. M., \& Mueller, J. S. 2007. Studying creativity, its processes, and its antecedents: An exploration of the componential theory of creativity. In J. Zhou \& C. Shalley (Eds.), Handbook of organizational creativity: 31-62. Mahwah, NJ: Erlbaum.

Axtell, C. M., Parker, S. K., Holman, D., \& Totterdell, P. 2007. Enhancing customer service: Perspective taking in a call centre. European Journal of Work and Organizational Psychology, 16: 141-168.

Barron, F. 1963. Creativity and psychological health: Origins of personality vitality and creative freedom. Princeton, NJ: Van Nostrand.

Batson, C. D. 1998. Altruism and prosocial behavior. In D. T. Gilbert, S. T. Fiske, \& G. Lindzey (Eds.), The handbook of social psychology (4th ed.), vol. 2: 282-316. New York: McGraw-Hill.

Batson, C. D., Ahmad, N., Powell, A. A., \& Stocks, E. L. 2008. Prosocial motivation. In J. Y. Shah \& W. L. Gardner (Eds.), Handbook of motivation science: 135-149. New York: Guilford Press.

Batson, C. D., Early, S., \& Salvarani, G. 1997. Perspective taking: Imagining how another feels versus imagining how you would feel. Personality and Social Psychology Bulletin, 23: 751-757.

Boland, R. J., Jr., \& Tenkasi, R. V. 1995. Perspective making and perspective taking in communities of knowing. Organization Science, 6: 350-372.

Brief, A. P., \& Motowidlo, S. J. 1986. Prosocial organizational behaviors. Academy of Management Review, 11: $710-725$.

Campbell, D. T. 1960. Blind variation and selective re- 
tention in creative thought as in other knowledge processes. Psychological Review, 67:380-400.

Caruso, E., Epley, N., \& Bazerman, M. H. 2006. The costs and benefits of undoing egocentric responsibility assessments in groups. Journal of Personality and Social Psychology, 91: 857-871.

Côté, S., \& Miners, C. T. H. 2006. Emotional intelligence, cognitive intelligence, and job performance. Administrative Science Quarterly, 51: 1-28.

Csikszentmihalyi, M. 1996. Creativity: Flow and the psychology of discovery and invention. New York: Harper Collins.

Csikszentmihalyi, M., \& Getzels, J. W. 1971. Discoveryoriented behavior and the originality of creative products: A study with artists. Journal of Personality and Social Psychology, 19: 47-52.

Davis, M. H., Conklin, L., Smith, A., \& Luce, C. 1996. Effect of perspective taking on the cognitive representation of persons: A merging of self and other. Journal of Personality and Social Psychology, 70: 713-726.

Deci, E. L., Koestner, R., \& Ryan, R. M. 1999. A metaanalytic review of experiments examining the effects of extrinsic rewards on intrinsic motivation. Psychological Bulletin, 125:627-668.

De Dreu, C. K. W. 2006. Rational self-interest and other orientation in organizational behavior: A critical appraisal and extension of Meglino and Korsgaard (2004). Journal of Applied Psychology, 91: 12451252.

De Dreu, C. K. W., \& Nauta, A. 2009. Self-interest and other-orientation in organizational behavior: Implications for job performance, prosocial behavior, and personal initiative. Journal of Applied Psychology, 94: 913-926.

De Dreu, C. K. W., Weingart, L. R., \& Kwon, S. 2000. Influence of social motives on integrative negotiation: A meta-analytic review and test of two theories. Journal of Personality and Social Psychology, 78: 889-905.

Dewett, T. 2007. Linking intrinsic motivation, risk taking, and employee creativity in an R\&D environment. R\&D Management, 37: 197-208.

Donnellan, M. B., Oswald, F. L., Baird, B. M., \& Lucas, R. E. 2006. The mini-IPIP scales: Tiny-yet-effective measures of the Big Five factors of personality. Psychological Assessment, 18: 192-203.

Dougherty, D. 1992. Interpretive barriers to successful product innovation in large firms. Organization Science, 3: 179-202.

Edmondson, A. 1999. Psychological safety and learning behavior in work teams. Administrative Science Quarterly, 44: 350-83.

Edwards, J. R., \& Lambert, L. S. L. 2007. Methods for integrating moderation and mediation: A general an- alytical framework using moderated path analysis. Psychological Methods, 12: 1-22.

Eisenberger, R., \& Aselage, J. 2009. Incremental effects of reward on experienced performance pressure: Positive outcomes for intrinsic interest and creativity. Journal of Organizational Behavior, 30: 95-117.

Eisenberger, R., \& Rhoades, L. 2001. Incremental effects of reward on creativity. Journal of Personality and Social Psychology, 81: 728-741.

Elsbach, K. D., \& Hargadon, A. B. 2006. Enhancing creativity through "mindless" work: A framework of workday design. Organization Science, 17: 470483.

Ford, C. M., \& Gioia, D. A. 2000. Factors influencing creativity in the domain of managerial decision making. Journal of Management, 26: 705-732.

Fredrickson, B. L. 1998. What good are positive emotions? Review of General Psychology, 2: 300-319.

Fuller, R. B., \& Kuromiya, K. 1981. Critical path. New York: St. Martin's Press.

Gagné, M., \& Deci, E. L. 2005. Self-determination theory and work motivation. Journal of Organizational Behavior, 26: 331-362.

Galinsky, A. D., Maddux, W. W., Gilin, D., \& White, J. B. 2008. Why it pays to get inside the head of your opponent: The differential effects of perspective taking and empathy in negotiations. Psychological Science, 19: 378-384.

Galinsky, A. D., Magee, J. C., Inesi, M. E., \& Gruenfeld, D. H. 2006. Power and perspectives not taken. Psychological Science, 17: 1068-1074.

George, J. M. 2007. Creativity in organizations. In J. P. Walsh \& A. P. Brief (Eds.), Academy of Management annals, vol. 1: 439-477. New York: Erlbaum.

George, J. M., \& Zhou, J. 2001. When openness to experience and conscientiousness are related to creative behavior: An interactional approach. Journal of Applied Psychology, 86: 513-524.

Glynn, M. A. 1994. Effects of work task cues and play task cues on information processing, judgment, and motivation. Journal of Applied Psychology, 79: 3445.

Goncalo, J. A., \& Staw, B. M. 2006. Individualism-collectivism and group creativity. Organizational Behavior and Human Decision Processes, 100: 96-109.

Grant, A. M. 2007. Relational job design and the motivation to make a prosocial difference. Academy of Management Review, 32: 393-417.

Grant, A. M. 2008. Does intrinsic motivation fuel the prosocial fire? Motivational synergy in predicting persistence, performance, and productivity. Journal of Applied Psychology, 93: 48-58.

Grant, A. M., Campbell, E. M., Chen, G., Cottone, K., Lapedis, D., \& Lee, K. 2007. Impact and the art of motivation maintenance: The effects of contact with 
beneficiaries on persistence behavior. Organizational Behavior and Human Decision Processes, 103: 53-67.

Grant, A. M., \& Sumanth, J. J. 2009. Mission possible? The performance of prosocially motivated employees depends on manager trustworthiness. Journal of Applied Psychology, 94: 927-944.

Hackman, J. R., Pearce, J. L., \& Wolfe, J. C. 1978. Effects of changes in job characteristics on work attitudes and behaviors: A naturally occurring quasi-experiment. Organizational Behavior and Human Performance, 21: 289-304.

Heath, C., Larrick, R. P., \& Klayman, J. 1998. Cognitive repairs: How organizations compensate for the shortcoming of individual learners. In B. M. Staw \& R. I. Sutton (Eds.), Research in organizational behavior, vol. 20: 1-37. Greenwich, CT: JAI Press.

Janssen, O., \& van Yperen, N. W. 2004. Employees' goal orientations, the quality of leader-member exchange, and the outcomes of job performance and job satisfaction. Academy of Management Journal, 47: $368-384$.

Kline, R. B. 1998. Principles and practice of structural equation modeling. New York: Guilford Press.

Koestner, R., Ryan, R. M., Bernieri, F., \& Holt, K. 1984. Setting limits on children's behavior: The differential effects of controlling vs. informational styles on intrinsic motivation and creativity. Journal of Personality, 52: 233-248.

Kunda, Z. 1990. The case for motivated reasoning. Psychological Bulletin, 108: 480-498.

Latham, G. P., Erez, M., \& Locke, E. A. 1988. Resolving scientific disputes by the joint design of crucial experiments by the antagonists: Application to the Erez-Latham dispute regarding participation of goal setting. Journal of Applied Psychology, 73: 753772 .

LeBreton, J. M., \& Senter, J. L. 2008. Answers to 20 questions about interrater reliability and interrater agreement. Organizational Research Methods, 11: 815-852.

Litchfield, R. C. 2008. Brainstorming reconsidered: A goal-based view. Academy of Management Review, 33: $649-668$.

Little, B. R. 2006. Prompt and circumstance: The generative contexts of personal projects analysis. In B. R. Little, K. Salmela-Aro, \& S. D. Phillips (Eds.), Personal project pursuit: Goals, action, and human flourishing: 3-50. Mahwah, NJ: Erlbaum.

Little, T. D., Cunningham, W. A., Shahar, G., \& Widaman, K. F. 2002. To parcel or not to parcel: Exploring the question, weighing the merits. Structural Equation Modeling, 9: 151-173.

MacKinnon, D. P., Fairchild, A. J., \& Fritz, M. S. 2007. Mediation analysis. In S. T. Fiske, A. E. Kazdin, \&
D. L. Schacter (Eds.), Annual review of psychology, vol. 58: 593-614. Palo Alto, CA: Annual Reviews.

Mathieu, J. E., \& Taylor, S. R. 2006. Clarifying conditions and decision points for mediational type inferences in organizational behavior. Journal of Organizational Behavior, 27: 1031-1056.

McAdams, D. P., \& de St. Aubin, E. 1992. A theory of generativity and its assessment through self-report, behavioral acts, and narrative themes in autobiography. Journal of Personality and Social Psychology, 62: 1003-1015.

Meglino, B. M., \& Korsgaard, M. A. 2004. Considering rational self-interest as a disposition: Organizational implications of other orientation. Journal of Applied Psychology, 89: 946-959.

Mohrman, S. A., Gibson, C. B., \& Mohrman, A. M., Jr. 2001. Doing research that is useful to practice: A model and empirical exploration. Academy of Management Journal, 44: 357-375.

Morgeson, F. P., \& Humphrey, S. E. 2006. The Work Design Questionnaire (WDQ): Developing and validating a comprehensive measure for assessing job design and the nature of work. Journal of Applied Psychology, 91: 1321-1339.

Nickerson, R. S. 1998. Confirmation bias: A ubiquitous phenomenon in many guises. Review of General Psychology, 2: 175-220.

Parker, S. K., \& Axtell, C. M. 2001. Seeing another viewpoint: Antecedents and outcomes of employee perspective taking. Academy of Management Journal, 44: 1085-1100.

Perry-Smith, J. E. 2006. Social yet creative: The role of social relationships in facilitating individual creativity. Academy of Management Journal, 49: 85-101.

Perry-Smith, J. E., \& Shalley, C. E. 2003. The social side of creativity: A static and dynamic social network perspective. Academy of Management Review, 28: 89-106.

Purser, R. E., Pasmore, W. A., \& Tenkasi, R. V. 1992. The influence of deliberations on learning in new product development teams. Journal of Engineering and Technology Management, 9(1): 1-28.

Ryan, R. M., \& Connell, J. P. 1989. Perceived locus of causality and internalization: Examining reasons for acting in two domains. Journal of Personality and Social Psychology, 57: 749-761.

Ryan, R. M., \& Deci, E. L. 2000. Self-determination theory and the facilitation of intrinsic motivation, social development, and well-being. American Psychologist, 55: 68-78.

Ryan, R. M., Koestner, R., \& Deci, E. L. 1991. Varied forms of persistence: When free-choice behavior is not intrinsically motivated. Motivation and Emotion, 15(3): 185-205.

Schutte, N. S., Malouff, J. M., Bobik, C., Coston, T. D., Greeson, C., Jedlicka, C., Rhodes, E., \& Wendorf, G. 
2001. Emotional intelligence and interpersonal relations. Journal of Social Psychology, 14: 523-536.

Schwartz, S. H., \& Bardi, A. 2001. Value hierarchies across cultures: Taking a similarities perspective. Journal of Crosscultural Psychology, 32: 268-290.

Sethi, R., \& Nicholson, C. Y. 2001. Structural and contextual correlates of charged behavior in product development teams. Journal of Product Innovation Management, 18: 154-168.

Shalley, C. E., \& Perry-Smith, J. E. 2001. Effects of socialpsychological factors on creative performance: The role of informational and controlling expected evaluation and modeling experience. Organizational Behavior and Human Decision Processes, 84: 1-22.

Shalley, C. E., Zhou, J., \& Oldham, G. R. 2004. The effects of personal and contextual characteristics on creativity: Where should we go from here? Journal of Management, 30: 933-958.

Shin, S., \& Zhou, J. 2003. Transformational leadership, conservation, and creativity: Evidence from Korea. Academy of Management Journal, 46: 703-714.

Silvia, P. 2008. Interest: The curious emotion. Current Directions in Psychological Science, 17: 57-60.

Simonton, D. K. 1989. The swan-song phenomenon: Lastworks effects for 172 classical composers. Psychology and Aging, 4: 42-47.

Simonton, D. K. 2003. Scientific creativity as constrained stochastic behavior: The integration of product, person, and process perspectives. Psychological Bulletin, 129: 475-494.
Tierney, P., Farmer, S. M., \& Graen, G. B. 1999. An examination of leadership and employee creativity: The relevance of traits and relationships. Personnel Psychology, 52: 591-620.

Zalesny, M. D., \& Ford, J. K. 1990. Extending the social information processing perspective: New links to attitudes, behaviors, and perceptions. Organizational Behavior and Human Decision Processes, 47: 205246.

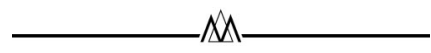

Adam M. Grant (grantad@wharton.upenn.edu) is an associate professor of management at The Wharton School at the University of Pennsylvania. He received his Ph.D. from the University of Michigan. His research focuses on work motivation, job design, prosocial helping and giving behaviors, initiative and proactive behaviors, and employee well-being.

James W. Berry (james_berry@unc.edu) is a doctoral candidate in organizational behavior at the Kenan-Flagler Business School at the University of North Carolina at Chapel Hill. He received his M.A. from the University of Florida. His research focuses primarily on creativity, judgments of creativity, humor, and resistance to change. He seeks to understand how new ideas are generated, how they are evaluated, and how they become assimilated within organizations. 